\title{
Clinical value of miR-198-5p in lung squamous cell carcinoma assessed using microarray and RT-qPCR
}

Yue-ya Liang ${ }^{1 \dagger}$, Jia-cheng Huang ${ }^{1 \dagger}$, Rui-xue Tang ${ }^{1}$, Wen-jie Chen ${ }^{1}$, Peng Chen ${ }^{1}$, Wei-luan Cen ${ }^{1}$, Ke Shi', Li Gao ${ }^{1}$, Xiang Gao', An-gui Liu', Xiao-tong Peng ${ }^{1}$, Gang Chen ${ }^{1}$, Su-ning Huang ${ }^{2}$, Ye-ying Fang ${ }^{2^{*}}$ (D) and Yong-yao Gu ${ }^{1{ }^{*}}$

\begin{abstract}
Background: To examine the clinical value of miR-198-5p in lung squamous cell carcinoma (LUSC).

Methods: Gene Expression Omnibus (GEO) microarray datasets were used to explore the miR-198-5p expression and its diagnostic value in LUSC. Real-time reverse transcription quantitative polymerase chain reaction was used to evaluate the expression of miR-198-5p in 23 formalin-fixed, paraffin-embedded (FFPE) LUSC tissues and corresponding non-cancerous tissues. The correlation between miR-198-5p expression and clinic pathological features was assessed. Meanwhile, putative target messenger RNAs of miR-198-5p were identified based on the analysis of differentially expressed genes in the Cancer Genome Atlas (TCGA) and 12 miRNA prediction tools. Subsequently, the putative target genes were sent to Gene Ontology and Kyoto Encyclopedia of Genes and Genomes pathway analyses.
\end{abstract}

Results: MiR-198-5p was low expressed in LUSC tissues. The combined standard mean difference (SMD) values of miR-198-5p expression based on GEO datasets were -0.30 (95\% confidence interval $(\mathrm{Cl})-0.54,-0.06)$ and $-0.39(95 \% \mathrm{Cl}-0.83,0.05)$ using fixed effect model and random effect model, respectively. The sensitivity and specificity were not sufficiently high, as the area under the curve (AUC) was $0.7749\left(Q^{*}=0.7143\right)$ based on summarized receiver operating characteristic (SROC) curves constructed using GEO datasets. Based on the in-house RT-qPCR, miR-198$5 p$ expression was $4.3826 \pm 1.7660$ in LUSC tissues and $4.4522 \pm 1.8263$ in adjacent normal tissues $(P=0.885)$. The expression of miR-198-5p was significantly higher in patients with early TNM stages (I-II) than that in cases with advanced TNM stages (III-IV) (5.4400 \pm 1.5277 vs $3.5690 \pm 1.5228, P=0.008)$. Continuous variable-based meta-analysis of GEO and PCR data displayed the SMD values of $-0.26(95 \% \mathrm{Cl}-0.48,-0.04)$ and $-0.34(95 \% \mathrm{Cl}-0.71,0.04)$ based on fixed and random effect models, respectively. As for the diagnostic value of miR-198-5p, the AUC based on the SROC curve using GEO and PCR data was $0.7351\left(Q^{*}=0.6812\right)$. In total, 542 genes were identified as the targets of miR-198$5 \mathrm{p}$. The most enriched Gene Ontology terms were epidermis development among biological processes, cell junction among cellular components, and protein dimerization activity among molecule functions. The pathway of non-small cell lung cancer was the most significant pathway identified using Kyoto Encyclopedia of Genes and Genomes analysis.

Conclusion: The expression of miR-198-5p is related to the TNM stage. Thus, miR-198-5p might play an important role via its target genes in LUSC.

Keywords: MiR-198-5p, Expression, Lung squamous cell carcinoma, Target genes, Bioinformatics

\footnotetext{
* Correspondence: fangyeying2010@aliyun.com; gyy_613@sina.com

${ }^{\dagger}$ Equal contributors

2Department of Radiotherapy, First Affiliated Hospital of Guangxi Medical

University, Nanning, Guangxi, People's Republic of China

${ }^{1}$ Department of Pathology, First Affiliated Hospital of Guangxi Medical

University, Nanning, Guangxi, People's Republic of China
} 


\section{Background}

Lung cancer ranks first among all cancers in terms of incidence, and it is also the most important cause of cancer death all over the world [1]. Non-small cell lung cancer (NSCLC) accounts for around 85\% of all lung cancers, with $30 \%$ of NSCLC cases being classified as lung squamous cell carcinoma (LUSC) [2-7]. Many patients are diagnosed with NSCLC at an advanced phase, which is attributable for the high mortality [8]. Therefore, more effective biomarkers are urgently needed in LUSC.

MicroRNAs (miRNAs) are $\sim 22$-nt long endogenous RNAs that play significant roles in various cellular processes [9]. Previous studies have shown that miRNAs can target mRNAs involved in most of the developmental processes and are thus associating with many diseases [10]. Moreover, miRNAs have also been found to be involved in cancer [11]. Studies have found that miR198-5p plays a vital role in many human cancers, including lung cancer [12]. A previous study [12] investigated the relationship between FGFR1 and miR-198-5p. However, the expression pattern of miR-198-5p in LUSC remains unknown. Additionally, the prospective target genes of miR-198-5p in LUSC have not yet been identified. Therefore, the relationship between miR-198-5p and lung squamous cell carcinoma as well as the underlying mechanism remains unknown.

To evaluate the clinical significance of miR-198-5p in LUSC, we examined miR-198-5p expression in LUSC tissues and carried out additional specific analyses to uncover its clinicopathological role. Furthermore, we performed big data analysis based on the Gene Expression Omnibus (GEO) and the Cancer Genome Atlas (TCGA). Subsequently, bioinformatics examinations were conducted to investigate the probable mechanism of miR-198-5p in LUSC.

\section{Methods}

Retrieval of data and publications from TCGA and GEO

The flowchart representing the main design of our study is shown in Fig. 1. We downloaded miRNA expression data from the Cancer Genome Atlas (TCGA) associated with LUSC. All data were converted to a $\log 2$ scale. We also retrieved data from the Gene Expression Omnibus (GEO) and ArrayExpress to assess the expression pattern of miR-198-5p in LUSC and corresponding non-tumor samples. The search terms were as follows: "lung" OR "pulmonary" OR "respiratory" OR "bronchioles" OR "bronchi” OR "alveoli" OR "pneumocytes" OR "air way" $[\mathrm{MeSH}]$ ) AND ("cancer" OR "carcinoma” OR "tumor" OR "neoplas" OR "malignan" "squamous cell carcinoma" OR "adenocarcinoma" [MeSH] ) OR/AND ("MicroRNA" OR "miRNA" OR "MicroRNA" OR "Small Temporal RNA" OR "noncoding RNA" OR "ncRNA" OR "small RNA" [MeSH]). Datasets with expression levels of miR-198-5p in LUSC and corresponding non-tumor samples were included. Other types of tumor or other miRNA were excluded. The number of samples in the tumor and non-tumor groups was at least three. The expression level of miR-198-5p in the datasets was converted to a $\log 2$ scale. The number, mean, and standard deviation of miR-198-5p levels in the tumor and non-tumor groups were calculated. We also searched PubMed, Web of Science, Science Direct, Google Scholar, Ovid, LILACS, Wiley Online Library, EMBASE, Cochrane Central Register of Controlled Trials, Chong Qing VIP, CNKI, Wan Fang, and China Biology Medicine disc; however, no publications regarding miR-198-5p expression in LUSC were found in these databases.

\section{RT-qPCR}

After the formalin-fixed, paraffin-embedded (FFPE) sections were dewaxed, total RNA was achieved from these sections with the miRNeasy FFPE Kit (QIAGEN) according to manufacturer's instruction. The concentration of RNA was measured using Nanodrop 2000. MiR-191 (CAACGGAAUCCCAAAAGCAGCU) and miR103 (AGCAGCAUUGUACAGGGCUAUGA) were used as stably expressed control miRNAs as previously reported [13]. Applied Biosystems 7900 PCR system was used to perform real-time quantitative PCR and detect miR198-5p expression (GGUCCAGAGGGGAGAUAGGUUC). The relative expression of miR-198-5p was calculated using the formula $2^{-\Delta \mathrm{Cq}}$.

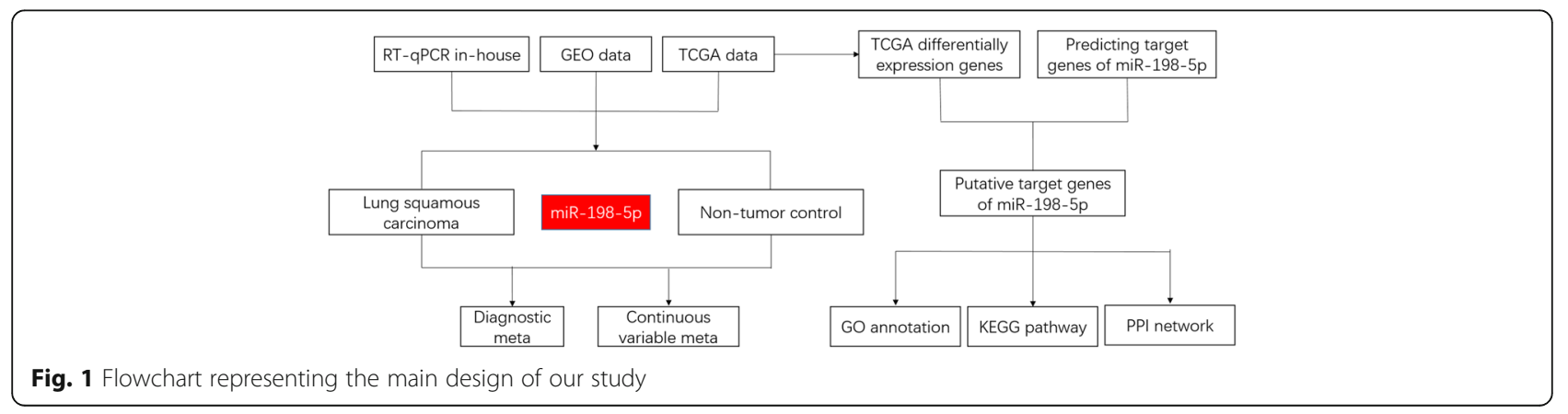




\section{Statistical analysis}

Paired sample $t$ test and independent sample $t$ test were performed using SPSS 23.0 to determine the association between miR-198-5p expression and various clinicopathological parameters based on real-time RT-qPCR and microarray data. $P<0.05$ was regarded as being statistically significant. Receiver operating characteristic (ROC) curves were constructed using SPSS 23.0.

Concerning the meta-analysis based on all accessible data, we used Stata 14 to determine the combined expression value of miR-198-5p in tumor and nontumor groups and its relationship with both standard

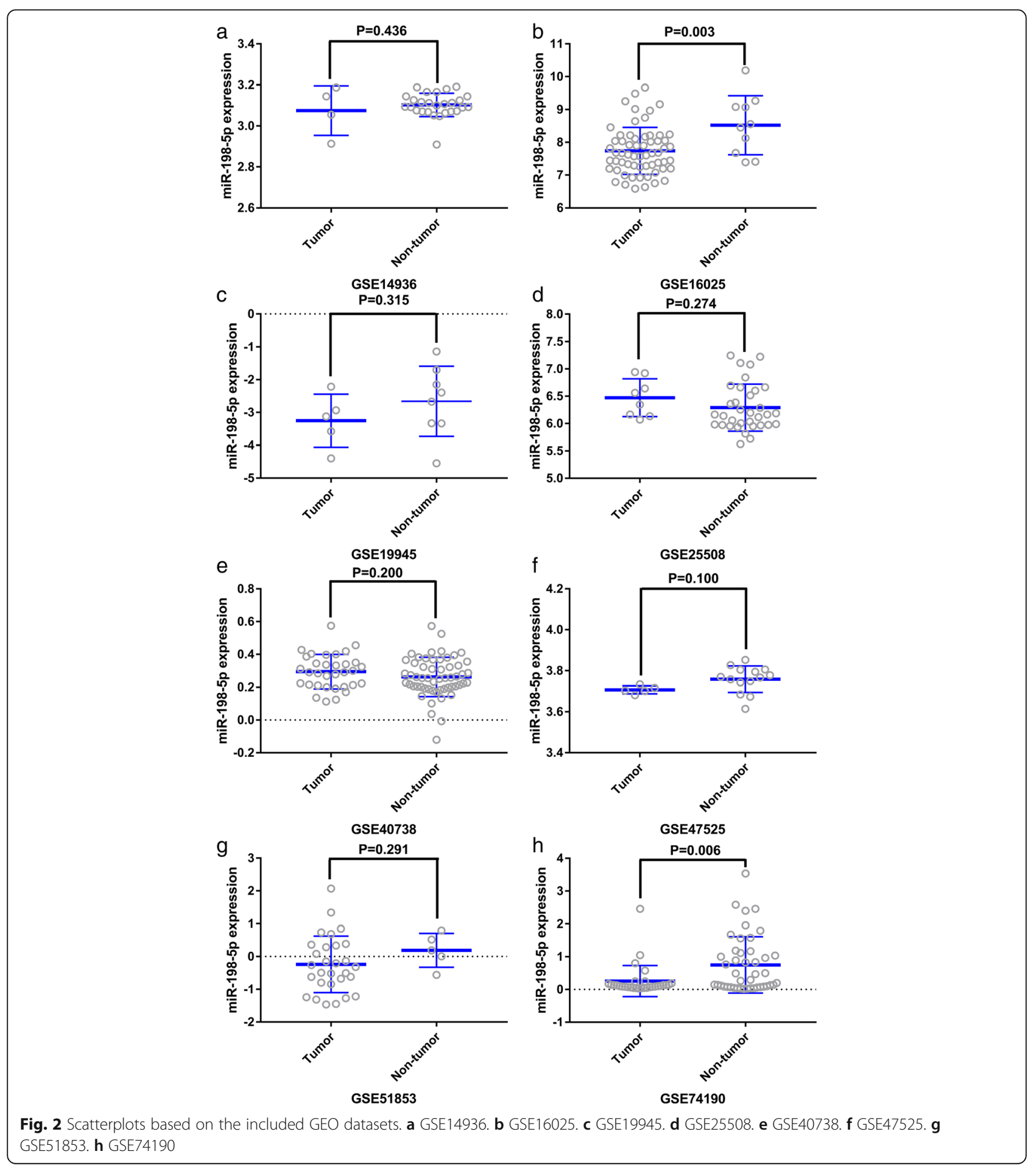




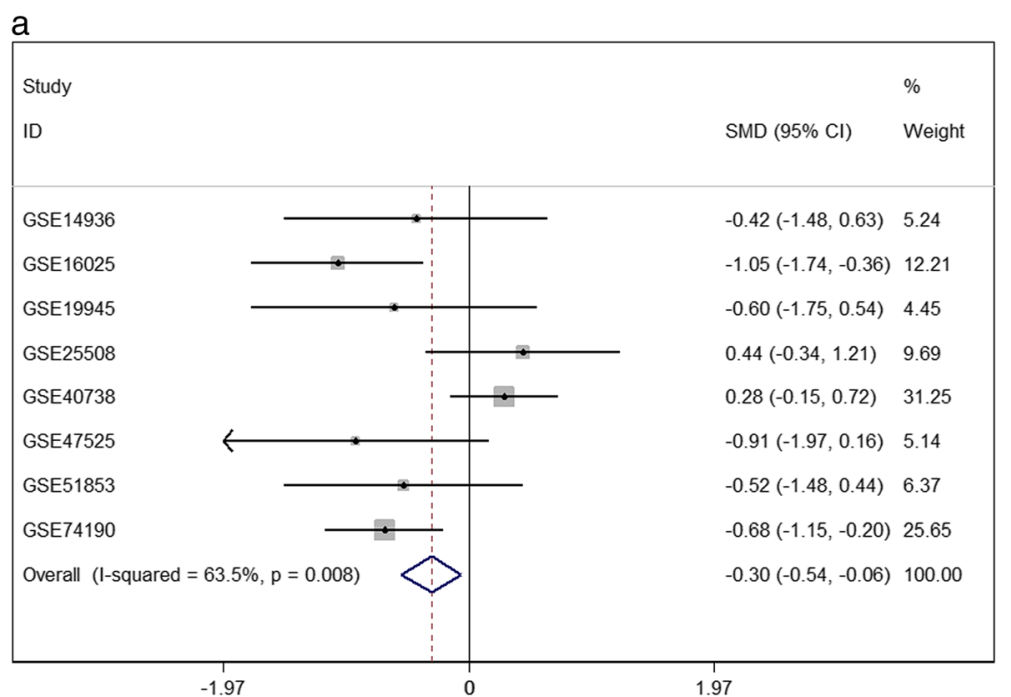

b

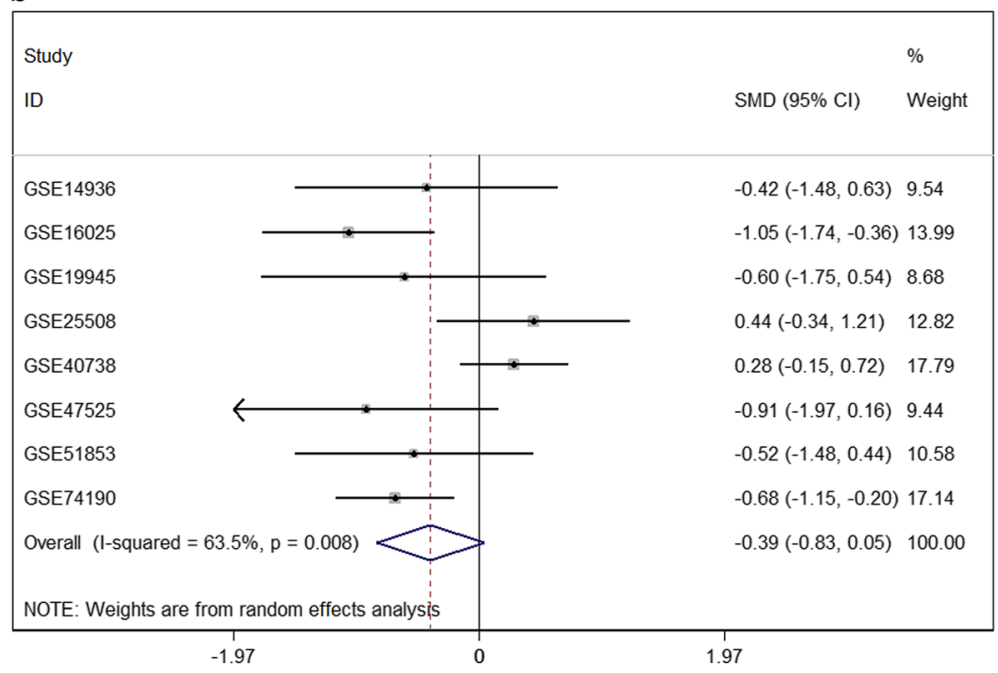

C

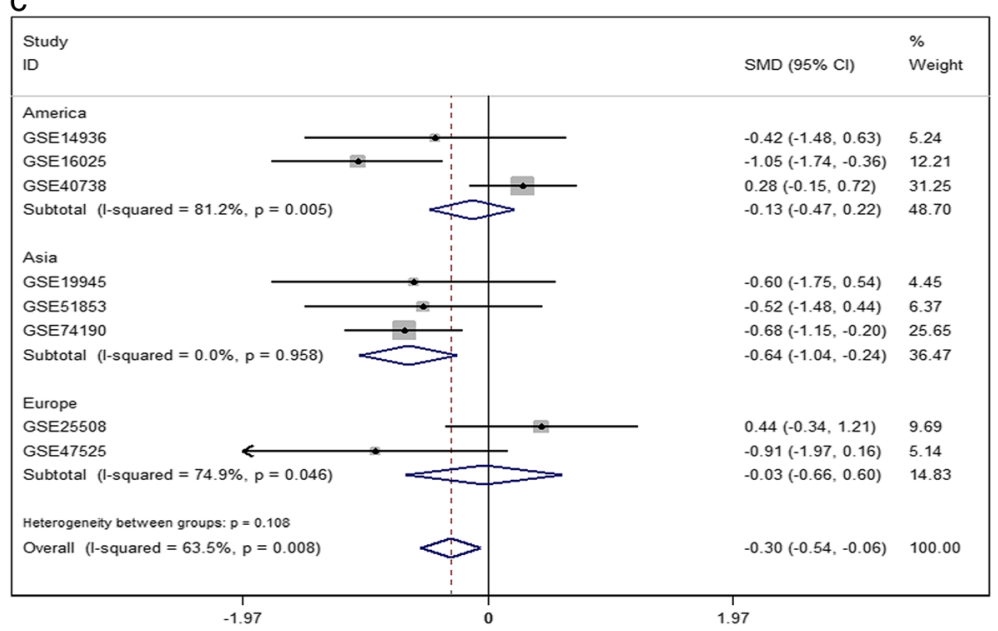

Fig. 3 Continuous variable meta-analysis based on GEO datasets. a Forest plot based on fixed effect model b Forest plot based on random effect model c Subgroup analysis by region 


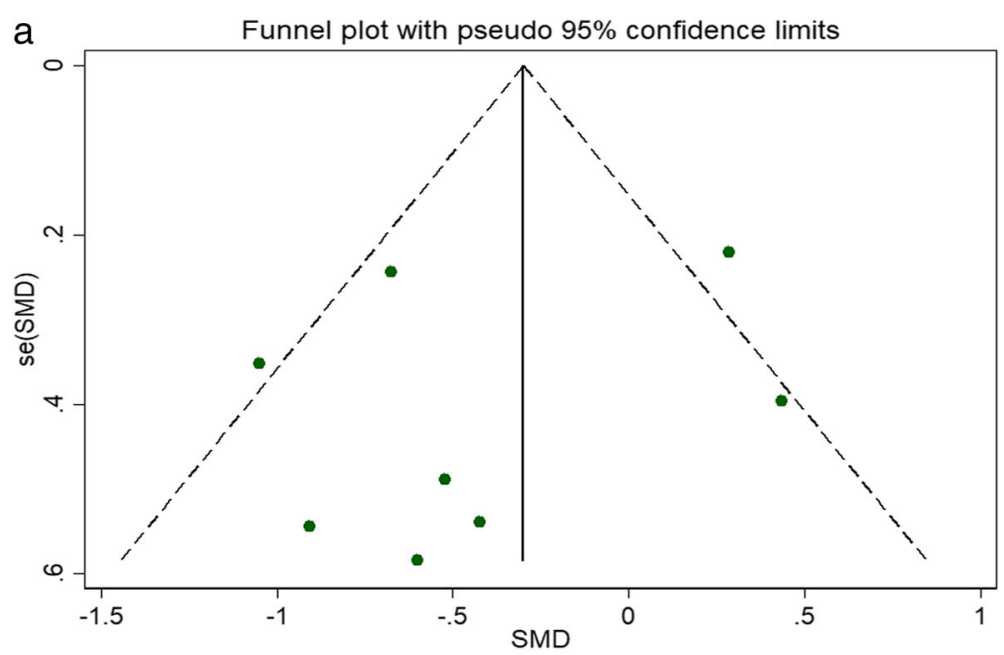

b

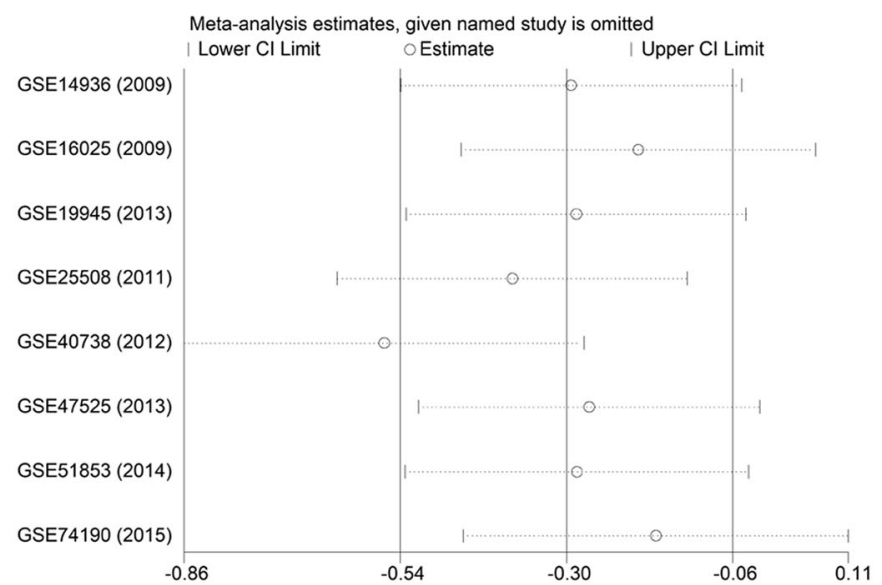

C

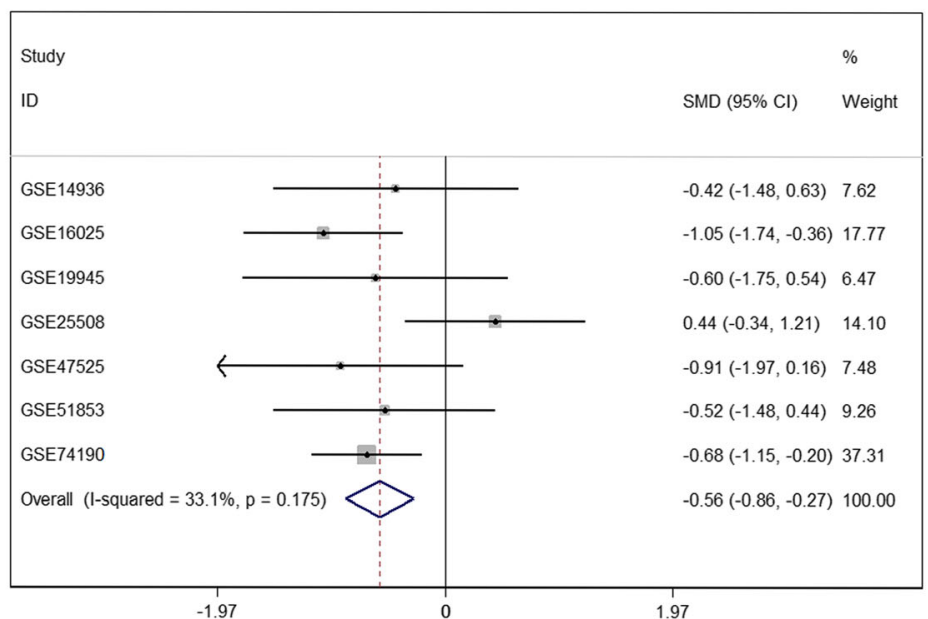

Fig. 4 Continuous variable meta-analysis based on GEO datasets. a Funnel plot. b Sensitivity analysis. c Forest plot after the elimination of GSE40738 

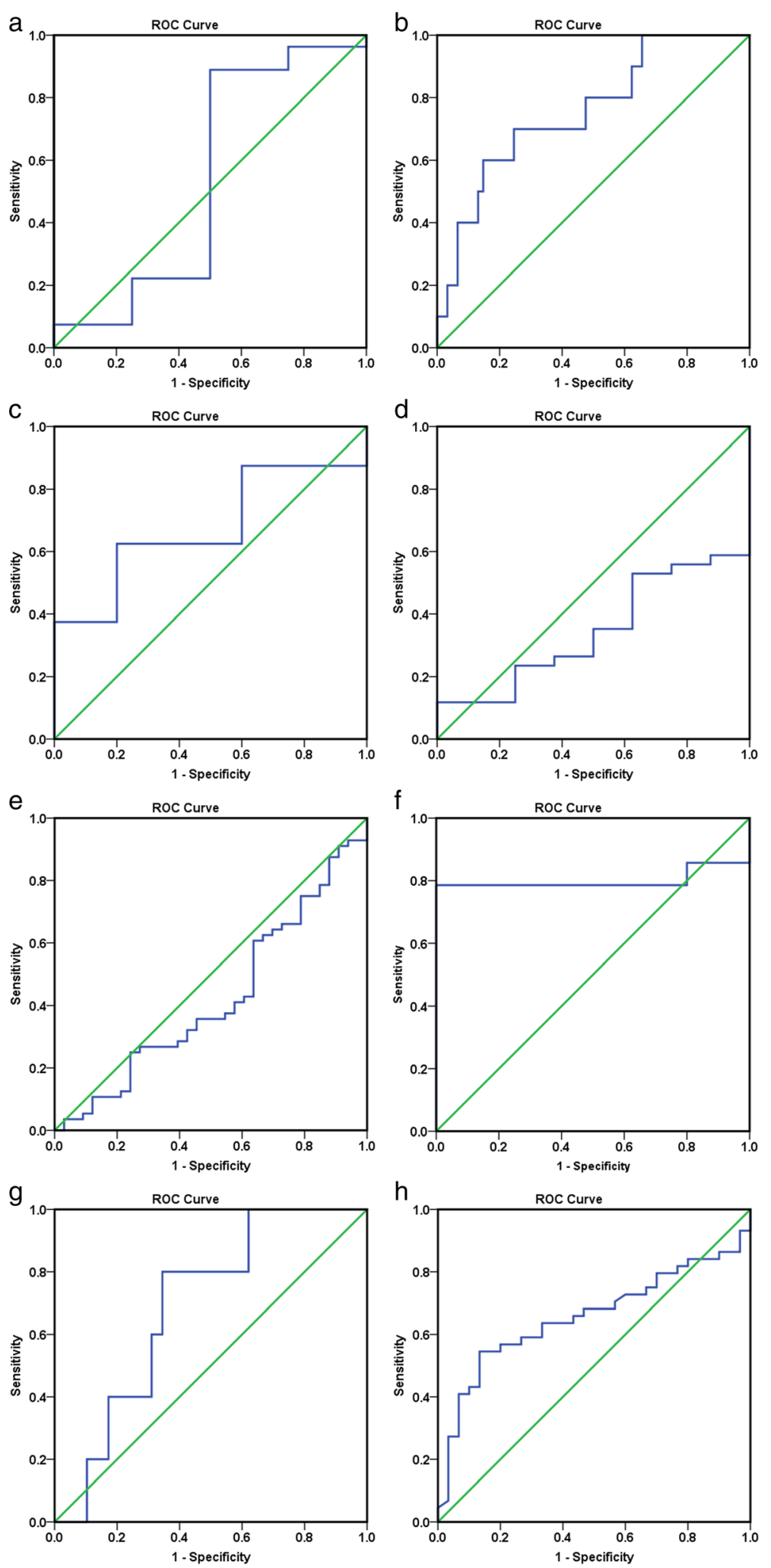

Fig. 5 Receiver operating characteristic (ROC) curves based on GEO datasets. a GSE14936. b GSE16025. c GSE19945. d GSE25508. e GSE40738. f GSE47525. $\mathbf{g}$ GSE51853. $\mathbf{h}$ GSE74190 


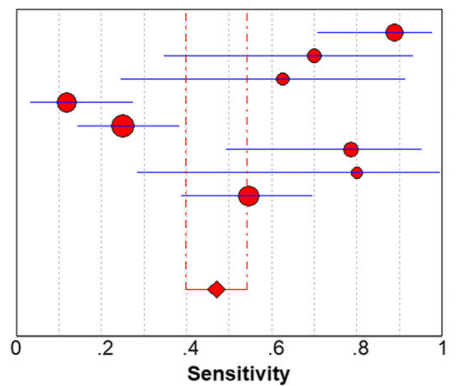

$\begin{array}{lll}\text { GSE14936 } & 0.89 & (0.71-0.98) \\ \text { GSE16025 } & 0.70 & (0.35-0.93) \\ \text { GSE19945 } & 0.63 & (0.24-0.91) \\ \text { GSE25508 } & 0.12 & (0.03-0.27) \\ \text { GSE40738 } & 0.25 & (0.14-0.38) \\ \text { GSE47525 } & 0.79 & (0.49-0.95) \\ \text { GSE51853 } & 0.80 & (0.28-0.99) \\ \text { GSE74190 } & 0.55 & (0.39-0.70)\end{array}$

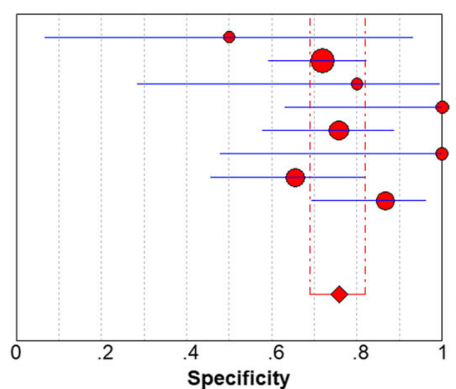

GSE14936

GSE16025

GSE19945

GSE25508

GSE40738

GSE47525

Pooled Sensitivity $=0.47(0.40$ to 0.54$)$

hi-square $=64.32 ; \mathrm{df}=7(p=0.0000)$

Inconsistency (I-square) $=89.1 \%$

GSE74190

Specificity $(95 \% \mathrm{Cl})$

$0.50 \quad(0.07-0.93)$

$0.72 \quad(0.59-0.82)$

$0.80 \quad(0.28-0.99)$

$1.00 \quad(0.63-1.00)$

$0.76 \quad(0.58-0.89)$

$1.00(0.48-1.00)$

$0.66 \quad(0.46-0.82)$

$0.87 \quad(0.69-0.96)$

Pooled Specificity $=0.76(0.69$ to 0.82$)$

Chi-square $=12.75 ; \mathrm{df}=7(\mathrm{p}=0.0784)$

Inconsistency (I-square) $=45.1 \%$

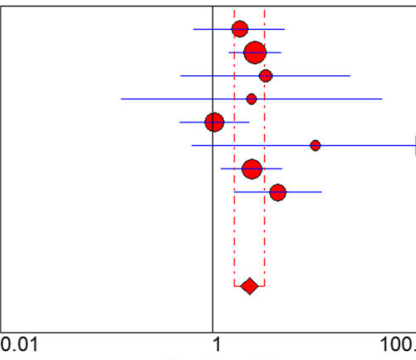

Positive LR (95\% Cl)

GSE14936

GSE16025

GSE19945

$1.78(0.66-4.78)$

$2.49(1.42-4.37)$

$3.13(0.50-19.55)$

$2.31 \quad(0.14-39.16)$

$1.03(0.48-2.19)$

$\begin{array}{lll}\text { GSE40738 } & 1.03 & (0.48-2.19) \\ \text { GSE51853 } & 9.20 & (0.64-132.64) \\ & 2.32 & (1.19-4.52)\end{array}$

GSE74190

$4.09 \quad(1.58-10.59)$

Random Effects Mode

Pooled Positive LR $=2.19$ (1.58 to 3.05)

Cochran $-Q=7.28 ; d f=7(p=0.4002)$

Positive LR

Tau-squared $=0.0094$

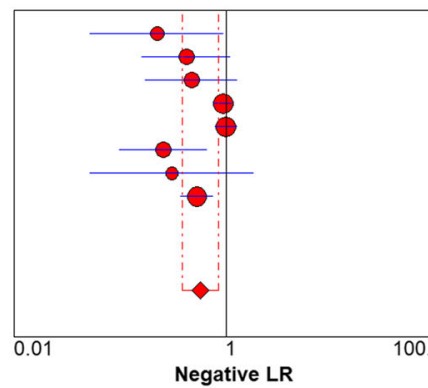

Negative LR $(95 \% \mathrm{Cl})$

$0.22(0.05-0.95)$

$0.42(0.16-1.09)$

$0.47 \quad(0.17-1.27)$

$0.92(0.75-1.13)$

$0.99 \quad(0.77-1.27)$

$0.25 \quad(0.10-0.66)$

$0.31 \quad(0.05-1.80)$

$0.52 \quad(0.37-0.75)$

GSE51853

GSE74190

Random Effects Mode

Pooled Negative LR $=0.57$ (0.38 to 0.84$)$

Cochran- $Q=31.75 ; d f=7(p=0.0000)$

Inconsistency (I-square) $=78.0 \%$

Tau-squared $=0.1826$

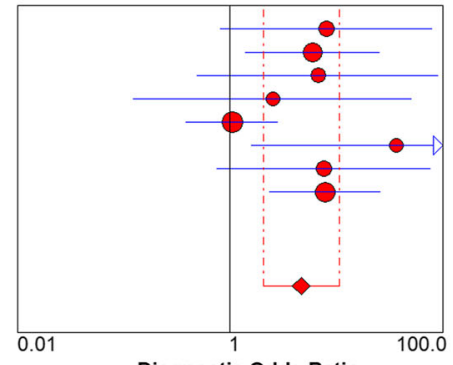

GSE14936

GSE16025

GSE19945

GSE25508

GSE40738

GSE 47525
Diagnostic OR $(95 \% \mathrm{Cl})$
$8.00 \quad(0.80-79.66)$
$5.96 \quad(1.39-25.63)$
$6.67 \quad(0.49-91.33)$
$2.51 \quad(0.12-51.35)$
$1.04(0.38-2.83)$
$36.14(1.58-828.86)$
$7.60(0.75-77.43)$

$\begin{array}{lll}\text { GSE74190 } & 7.80 \quad(2.33-26.12)\end{array}$

\section{Random Effects Model}

Pooled Diagnostic Odds Ratio $=4.64$ (2.04 to 10.56$)$

Cochran- $Q=11.15 ; d f=7(p=0.1321)$

Diagnostic Odds Ratio

Inconsistency (I-square) $=37.2 \%$

Tau-squared $=0.4776$

Fig. 6 Pooled sensitivity, specificity, positive likelihood ratio, negative likelihood ratio, diagnostic score, and odds ratio obtained using MetaDisc 1.4 based on GEO datasets 
mean difference (SMD) and summarized receiver operating characteristic (SROC). The fixed effect model was initially used. The random effect model was used when heterogeneity was detected. The data were considered heterogeneous when $I^{2}>50 \%$. Subgroup analysis and sensitivity analysis were carried out to find out the source of heterogeneity. We tested publication bias with funnel plots. SPSS 23.0 was employed to explore the diagnostic value of miR-198-5p in LUSC based on GEO data. Then, we performed a diagnostic metaanalysis using MetaDiSc 1.4. Meta-regression and threshold effect analysis were performed to determine the source of heterogeneity. The data from TCGA were not included in the analysis because of missing data.

\section{Differentially expressed mRNAs in LUSC based on TCGA}

The expression level of each mRNA transformed into the $\log 2$ scale was evaluated using DESeq R package. We obtained 9860 differentially expressed genes in LUSC, including 6092 upregulated and 3768 downregulated genes.

\section{Selection of putative target genes of miR-198-5p}

Predictions were conducted in silico with miRWalk 2.0 (http://zmf.umm.uni-heidelberg.de/apps/zmf/mirwalk2/). Genes that were present in more than 5 of the 12 prediction online tools were selected for further analysis. The selected genes were cross-referenced with the differentially expressed genes in TCGA. The overlapping genes were considered the putative targets of miR-198$5 p$ in LUSC.

\section{Bioinformatics analyses}

Gene Ontology (GO) annotation via DAVID (https:// david.ncifcrf.gov/) was performed, including biological processes (BP), cellular components (CC), and molecular functions (MF). The Kyoto Encyclopedia of Genes and Genomes (KEGG) pathways associated with the putative target genes were also analyzed in DAVID. The results of GO annotation and KEGG pathway analysis were visualized using BiNGO and EnrichmentMap plugins in Cytoscape version 3.5.0. We used STRING (https:// string-db.org/) to build interaction maps of the proteins encoded by the putative target genes.

\section{Validation of the putative target genes in the most significant KEGG pathway based on TCGA data}

We selected the genes in the most significant KEGG pathway "non-small cell lung cancer" for further analysis. The differences in the expression levels of E2F2, E2F3, TGFA, PRKCG, CDK6, EGF, and CDK4 between LUSC and non-tumor tissues were analyzed based on TCGA data.

\section{Results}

GEO data mining to determine the expression and diagnostic value of miR-198-5p

Considering the meta-analysis of miR-198-5p expressionbased GEO data, eight datasets were included in our study. The scatter plots based on the GEO datasets are shown in Fig. 2. Forest plots using both fixed effect model (Fig. 3a) and random effect model (Fig. 3b) represented the expression level of miR-198-5p in LUSC. The combined effect sizes were -0.30 (95\% CI $-0.54,-0.06)$ and -0.39 (95\% CI $-0.83,0.05)$ based on the fixed and random effect models, respectively. Subgroup analysis showed that there was no heterogeneity among the studies from Asia $\left(I^{2}=0.0 \%\right)$ (Fig. 3c). The corresponding funnel plot is shown in Fig. 4a $(P>0.05)$. Sensitivity analysis (Fig. 4b) showed that the dataset GSE40738 might be a source of heterogeneity. The forest plot after the removal of GSE40738 is shown in Fig. 4c. The adjusted combined SMD value was $-0.56(95 \% \mathrm{CI}-0.86,-0.27)$ with $I^{2}=33.1 \%$. The receiver operating characteristic curves based on the included datasets from GEO database are shown in Fig. 5. The pooled sensitivity, specificity, positive likelihood ratio, negative likelihood ratio, and diagnostic odds ratio were 0.47 (95\% CI $0.40,0.54$ ), 0.76 (95\% CI 0.69, 0.82), 2.19 (95\% CI 1.58, 3.05), 0.57 (95\% CI $0.38,0.84)$, and 4.64 (95\% CI 2.04, 10.56), respectively (Fig. 6). The area under the curve (AUC) based on the summarized receiver operating characteristic (SROC) curve was $0.7749\left(Q^{*}=0.7143\right)$ (Fig. 7). We did not find a threshold effect of miR-198-5p in the study $(P=0.058)$. Only study region was determined to be a covariant in the meta-regression, and thus it was likely not a source of heterogeneity $(P=0.0550)$ (Table 1$)$.

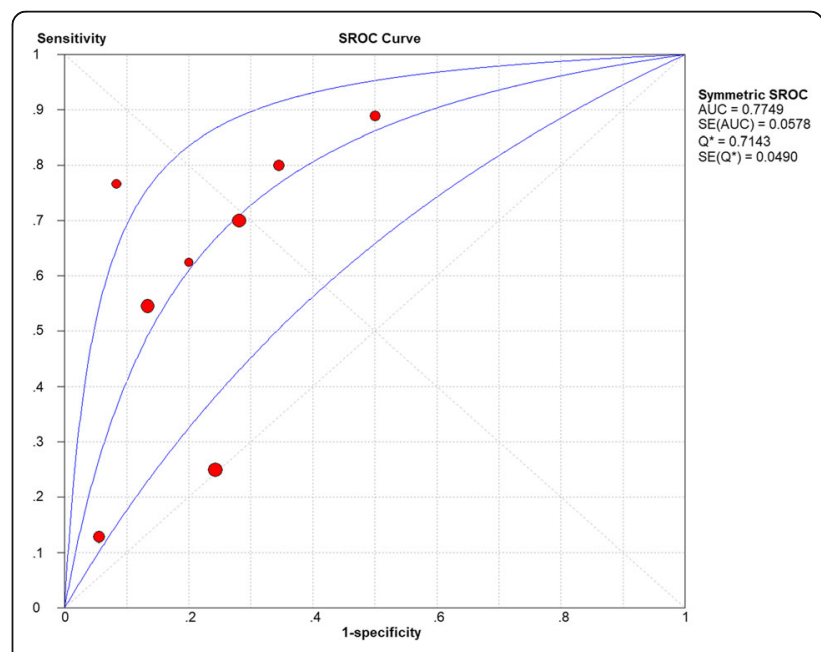

Fig. 7 Summarized receiver operating characteristic (SROC) curve of GEO datasets 
Table 1 Meta-regression based on GEO data

\begin{tabular}{llllll}
\hline Var & Coeff. & Std. Err. & $P$ value & RDOR & {$[95 \% \mathrm{Cl}]$} \\
\hline Cte. & 0.123 & 0.782 & 0.8816 & - & - \\
S & 0.5 & 0.2152 & 0.0679 & - & - \\
Region & 1.221 & 0.4899 & 0.055 & 3.39 & $(0.96 ; 11.95)$ \\
\hline
\end{tabular}

\section{Clinical value of miR-198-5p in LUSC assessed using RT-qPCR}

Using RT-qPCR, the expression of miR-198-5p in the LUSC tissues was $(4.3826 \pm 1.7660)$ compared with that in the non-tumor tissues $(4.4522 \pm 1.8263, P=0.885)$ (Fig. 8a, b). The other clinicopathological features of the LUSC case are shown in Table 2. Notably, the expression level of miR-198-5p in patients with early TNM stage (I-II) was $(5.4400 \pm 1.5277)$ compared to $(3.5690 \pm 1.5228)$ in patients with advanced TNM stage (III-IV) $(P=0.008)$ (Fig. 8c, d).

\section{Meta-analysis of miR-198-5p expression based on PCR and GEO data}

The combined SMD values based on GEO and PCR data were -0.26 (95\% CI - 0.48, - 0.04) (Fig. 9a) and - 0.34 (95\% CI -0.71, 0.04) (Fig. 9b) using the fixed and

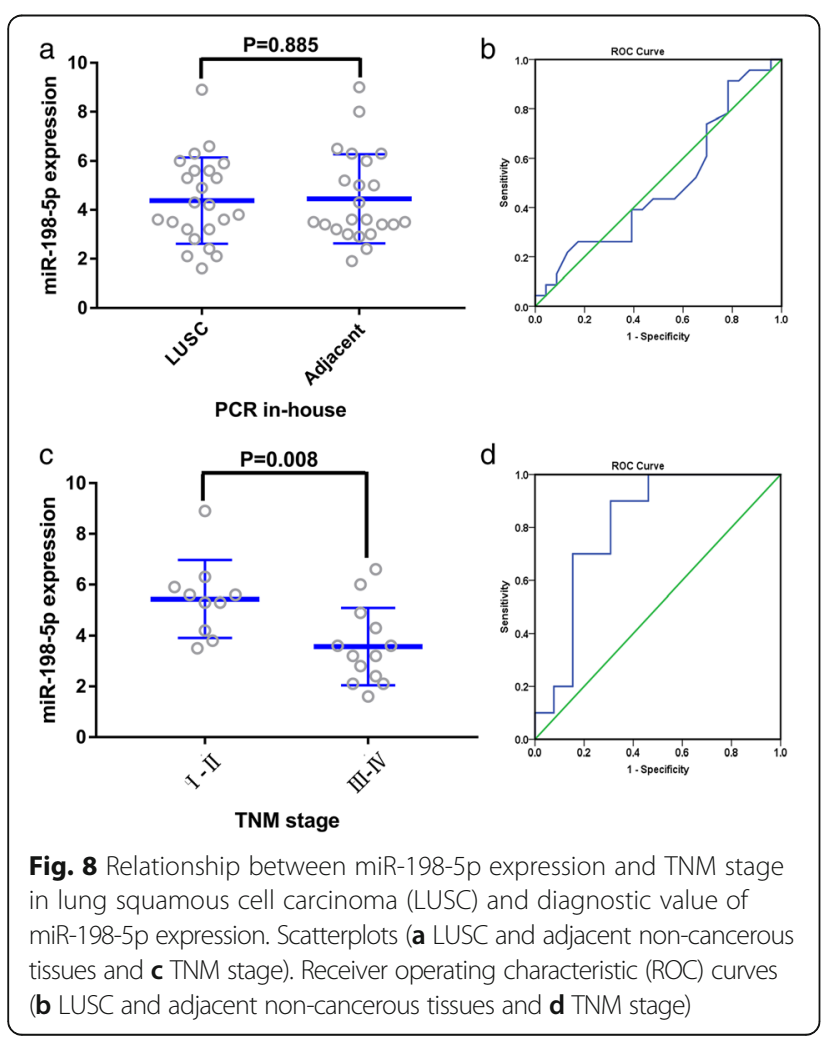

Table 2 Relationship between the expression of miR-198-5p and clinicopathological features in LUSC patients

\begin{tabular}{|c|c|c|c|c|c|}
\hline \multicolumn{2}{|c|}{ Clinicopathological feature } & \multirow{3}{*}{$\begin{array}{c}n \\
23\end{array}$} & \multicolumn{3}{|c|}{ miR-198-5p expression $\left(2^{-\Delta C q}\right)$} \\
\hline & & & \multirow{2}{*}{$\begin{array}{l}\text { Mean } \pm \text { SD } \\
4.3826 \pm 1.7660\end{array}$} & \multirow{2}{*}{$\frac{t}{0.146}$} & \multirow{2}{*}{$\frac{P}{0.885}$} \\
\hline Tissue & LUSC & & & & \\
\hline & Non-tumor & 23 & $4.4522 \pm 1.8263$ & & \\
\hline \multirow[t]{2}{*}{ Gender } & Male & 18 & $4.4670 \pm 1.8711$ & 0.425 & 0.675 \\
\hline & Female & 5 & $4.0800 \pm 1.4584$ & & \\
\hline \multirow[t]{2}{*}{ Age } & $<60$ & 15 & $4.0930 \pm 1.4270$ & -1.080 & 0.293 \\
\hline & $\geq 60$ & 8 & $4.9250 \pm 2.2833$ & & \\
\hline \multirow[t]{2}{*}{ Smoking state } & No & 12 & $4.3000 \pm 1.2884$ & -0.229 & 0.821 \\
\hline & Yes & 11 & $4.4730 \pm 2.2401$ & & \\
\hline \multirow[t]{2}{*}{ Size } & $\leq 3 \mathrm{~cm}$ & 7 & $4.2570 \pm 2.1196$ & -0.220 & 0.828 \\
\hline & $>3 \mathrm{~cm}$ & 16 & $4.4380 \pm 1.6633$ & & \\
\hline \multirow[t]{2}{*}{ EGFR amplification } & No & 17 & $4.7470 \pm 1.8084$ & 1.741 & 0.096 \\
\hline & Yes & 6 & $3.3500 \pm 1.2357$ & & \\
\hline \multirow[t]{2}{*}{ Vascular invasion } & No & 20 & $4.6100 \pm 1.6914$ & 1.656 & 0.113 \\
\hline & Yes & 3 & $2.8670 \pm 1.7786$ & & \\
\hline \multirow[t]{2}{*}{ TNM stage } & $|-| \mid$ & 10 & $5.4400 \pm 1.5277$ & 2.917 & 0.008 \\
\hline & III-IV & 13 & $3.5690 \pm 1.5228$ & & \\
\hline \multirow[t]{2}{*}{ LNM } & No & 11 & $4.8730 \pm 2.0553$ & 1.294 & 0.210 \\
\hline & Yes & 12 & $3.9330 \pm 1.3918$ & & \\
\hline \multirow[t]{2}{*}{ EGFR protein } & Low & 18 & $4.3280 \pm 1.9013$ & -0.277 & 0.785 \\
\hline & High & 5 & $4.5800 \pm 1.3142$ & & \\
\hline \multirow[t]{2}{*}{ MET } & Low & 13 & $4.9230 \pm 1.6559$ & 1.750 & 0.095 \\
\hline & High & 10 & $3.6800 \pm 1.7313$ & & \\
\hline \multirow[t]{2}{*}{ Grading } & $\|$ & 16 & $4.4130 \pm 1.8326$ & 0.12 & 0.906 \\
\hline & III & 7 & $4.3140 \pm 1.7411$ & & \\
\hline
\end{tabular}

random effect models, respectively. In subgroup analysis, no heterogeneity among the studies from Asia was observed $\left(I^{2}=0.0 \%\right)$ (Fig. 9c). The corresponding funnel plot is shown in Fig. 10a $(P>0.05)$. Once again, study region and the dataset GSE40738 were identified as sources of heterogeneity (Fig. 10b). After eliminating GSE40738 from the analysis, the SMD changed to -0.46 (95\% CI - 0.72, - 0.20) (Fig. 10c). The pooled sensitivity, specificity, positive likelihood ratio, negative likelihood ratio, and diagnostic odds ratio were $0.52(95 \%$ CI 0.45, 0.58), 0.70 (95\% CI 0.63, 0.76), 1.97 (95\% CI 1.25, 3.13), 0.56 (95\% CI 0.38, 0.82), and 4.23 (95\% CI 2.07, 8.64), respectively (Fig. 11). The area under the curve (AUC) based on the summarized receiver operating characteristic (SROC) curve was $0.7351 \quad\left(Q^{*}=0.6812\right)$ (Fig. 12). We also observed threshold effect of miR$198-5 p$ in this study $(P=0.013)$. In this case, study region was not accountable for heterogeneity $(P=0.2107)$ (Table 3). 
a

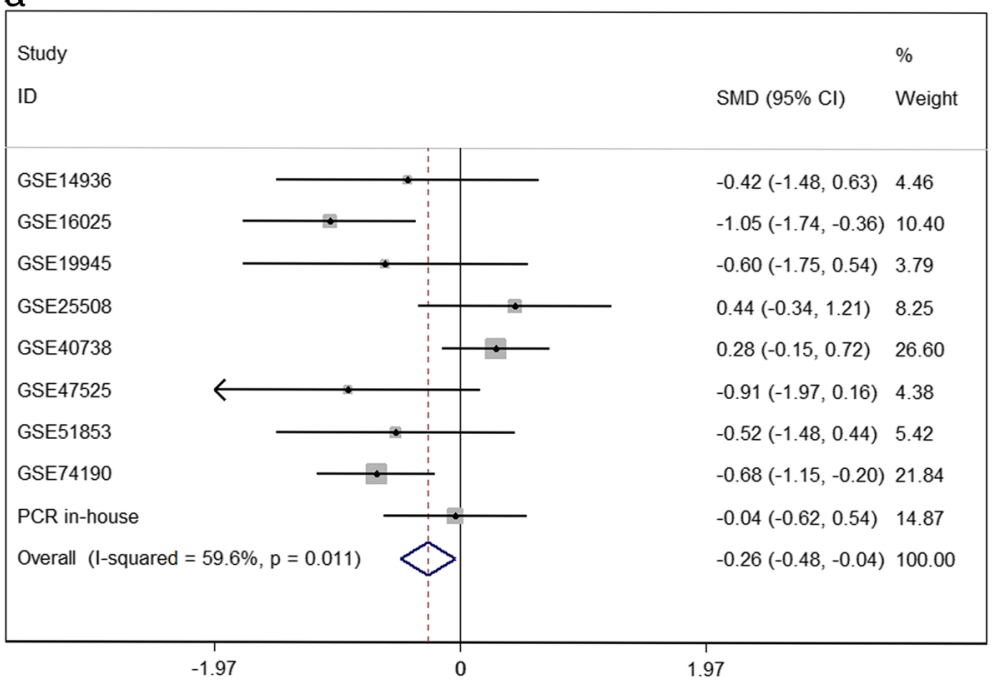

b

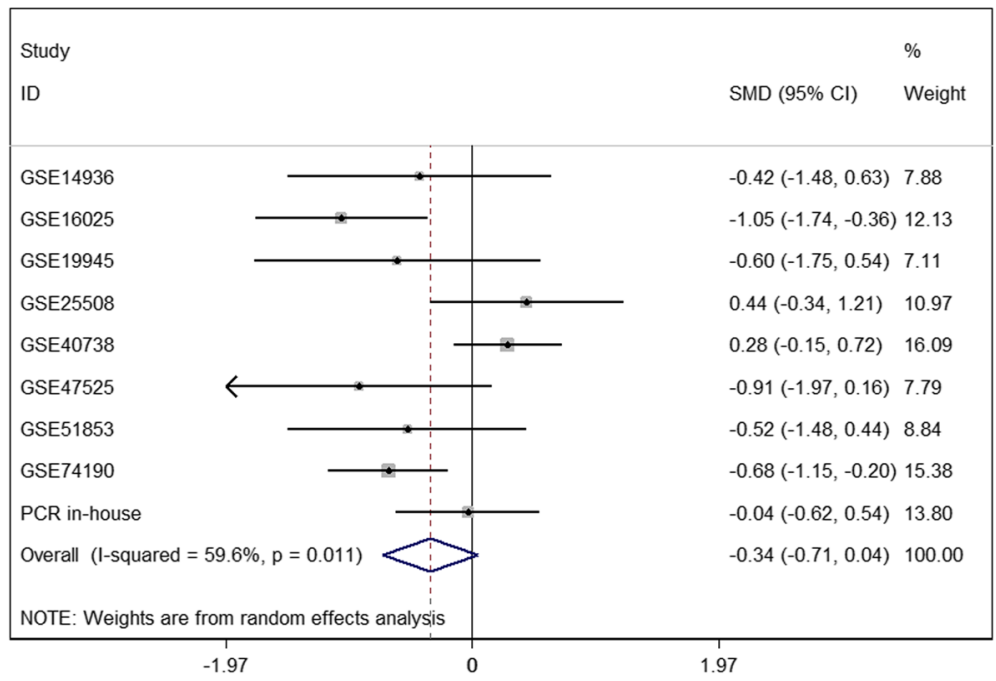

C

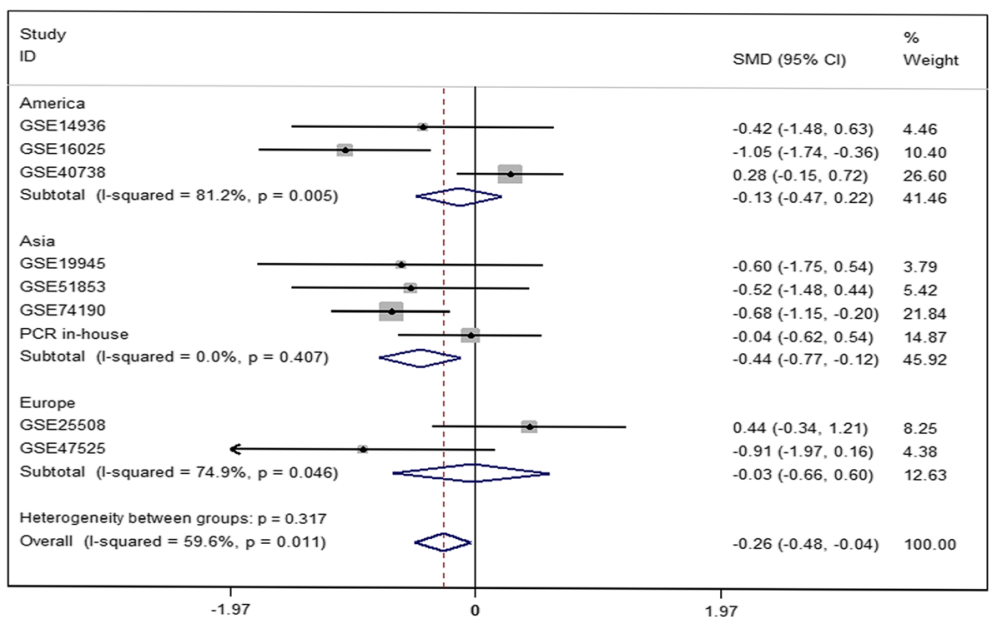

Fig. 9 Continuous variable meta-analysis based on GEO datasets and in-house RT-qPCR results. a: Forest plot based on fixed effect model, (b): forest plot based on random effect model, (c): subgroup analysis by region 


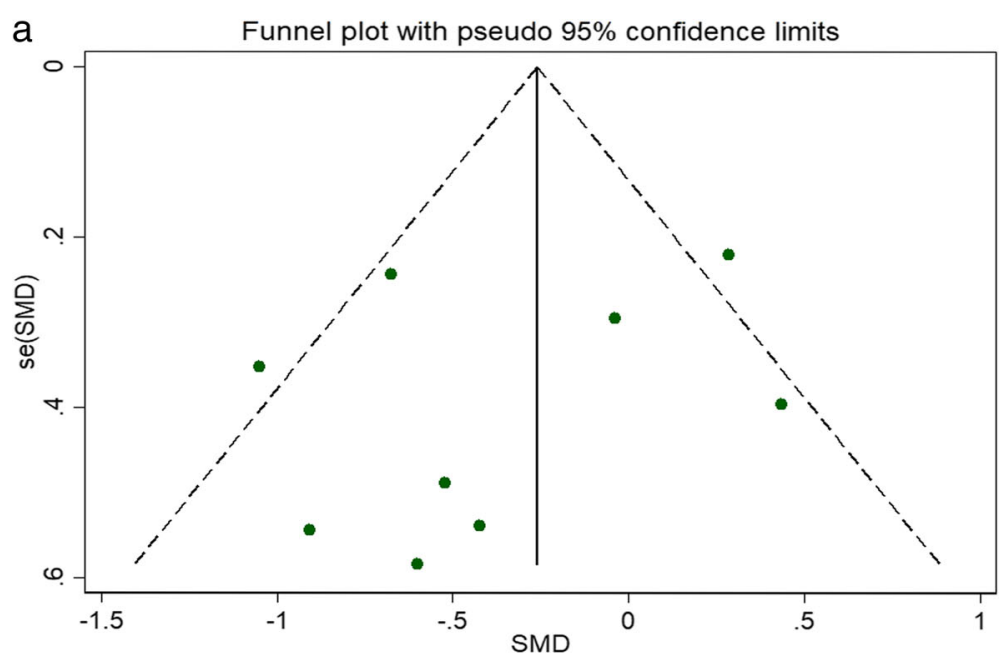

b

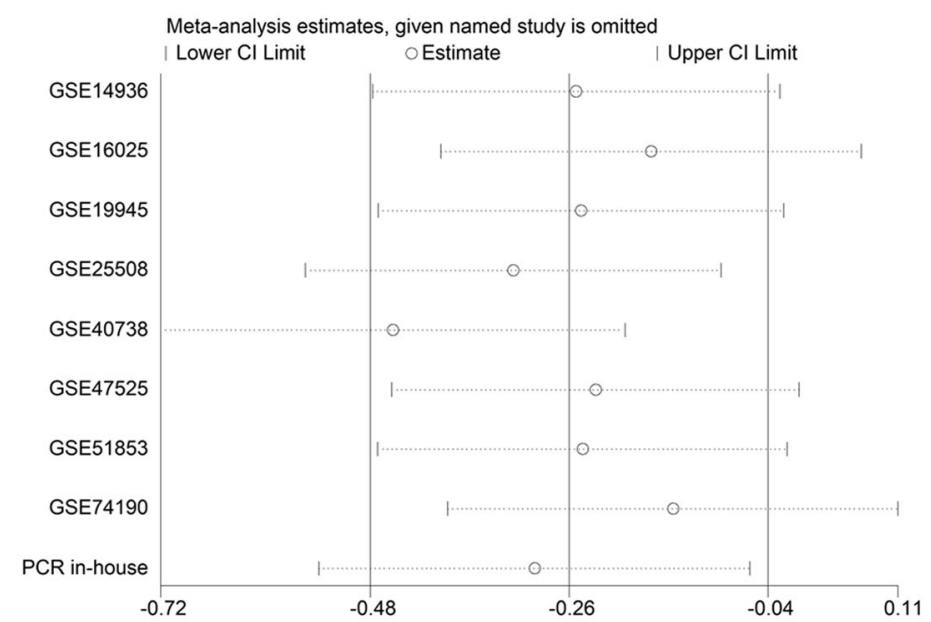

C

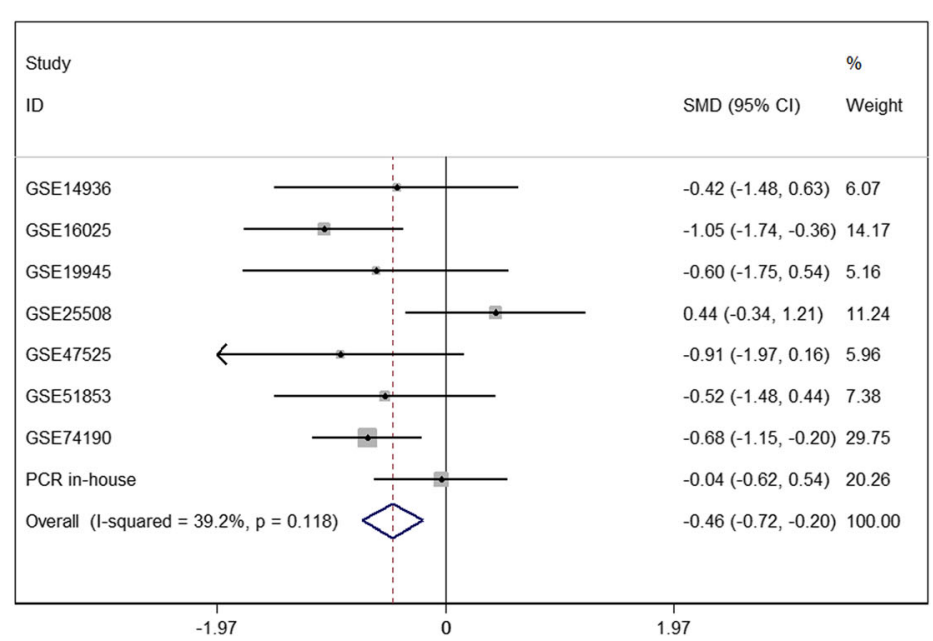

Fig. 10 Continuous variable meta-analysis based on GEO datasets and in-house RT-qPCR results. a Funnel plot. b Sensitivity analysis. c Forest plot after the elimination of GSE40738 


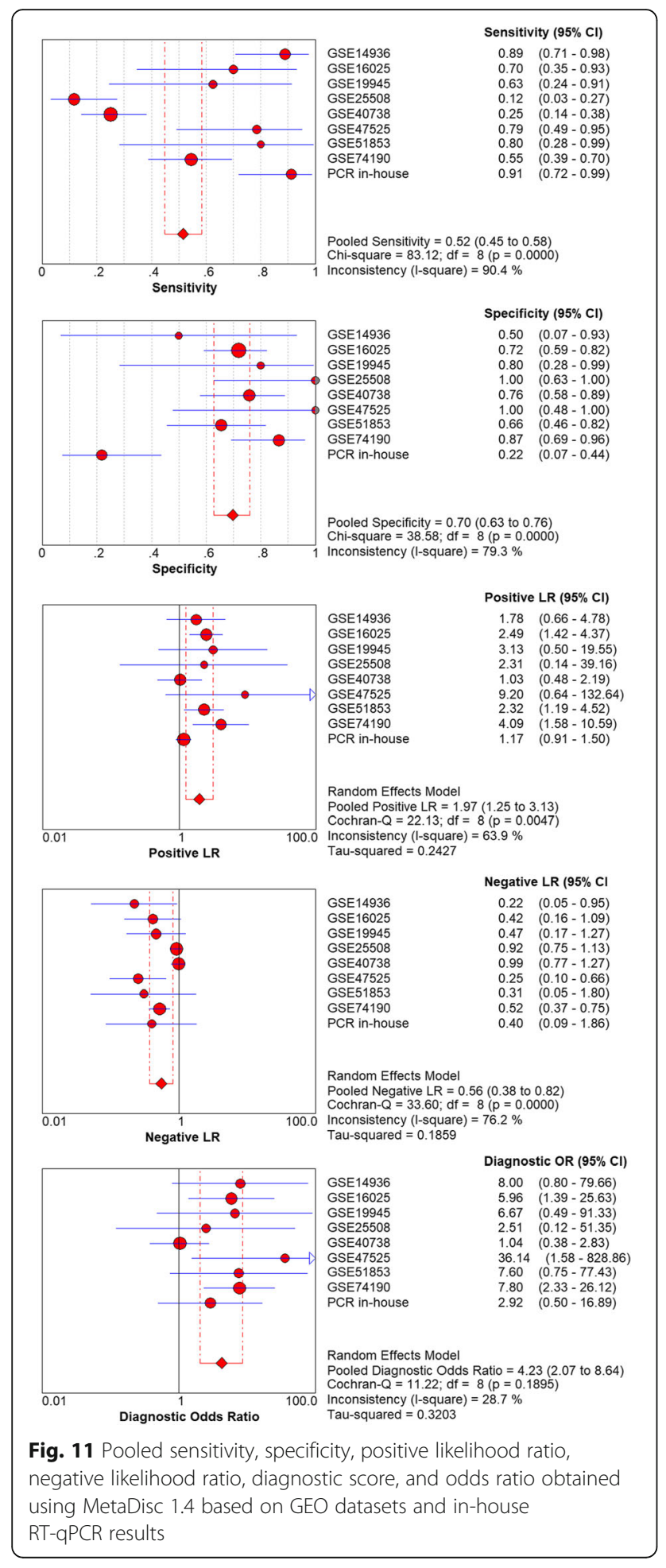

Gene Ontology (GO), Kyoto Encyclopedia of Genes and Genomes (KEGG) pathway annotation, and protein-protein interaction (PPI) network

In total, 542 genes were considered putative targets of miR-198-5p in LUSC (Fig. 13). Based on Gene Ontology

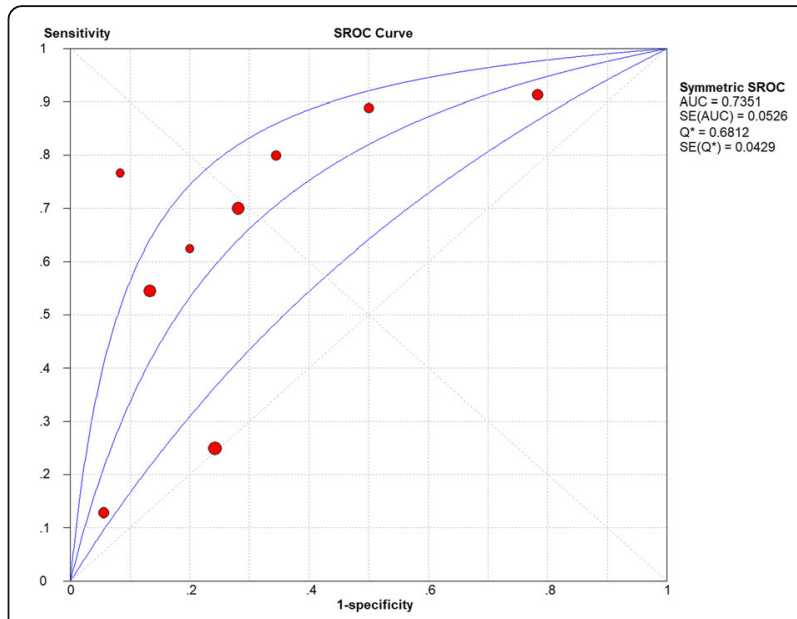

Fig. 12 Summarized receiver operating characteristic (SROC) curve of GEO datasets and in-house RT-qPCR results

(GO) analysis, the putative target genes of miR-198-5p were predominantly related to epidermis development with respect to biological processes $(P=4.84 \mathrm{E}-04)$ (Fig. 14, Table 4), cell junction in the case of cellular components $(P=7.60 \mathrm{E}-05)$ (Fig. 15, Table 4$)$, and protein dimerization activity regarding molecular functions $(P=8.03 \mathrm{E}-05)$ (Fig. 16, Table 4). In terms of the KEGG pathway, the putative target genes of miR-198-5p were associated with non-small cell lung cancer, pathways in cancer and pancreatic cancer (Fig. 17, Table 5). The protein-protein interaction (PPI) network is shown in Fig. 18. The seven chosen genes in the KEGG pathway "non-small cell lung cancer" were all significantly upregulated in the LUSC samples compared to the non-tumor samples based on TCGA data (Fig. 19, Fig. 20).

\section{Discussion}

MiR-198-5p was clearly under-expressed in LUSC tissues in comparison with non-cancer lung tissues. The cases with LUSC in Asia expressed lower levels of miR-198-5p than did the healthy controls; however, the expression pattern in other regions was unclear. Our RT-qPCR indicated that the expression of miR-198-5p might be related to the tumor TNM stage, which

Table 3 Meta-regression based on GEO and in-house RT-qPCR data

\begin{tabular}{llllll}
\hline Var & Coeff. & Std. Err. & $P$ value & RDOR & {$[95 \% \mathrm{Cl}]$} \\
\hline Cte. & 0.27 & 0.9327 & 0.7816 & - & - \\
S & 0.125 & 0.1632 & 0.4714 & - & - \\
Region & 0.751 & 0.5363 & 0.2107 & 2.12 & $(0.57 ; 7.88)$ \\
\hline
\end{tabular}




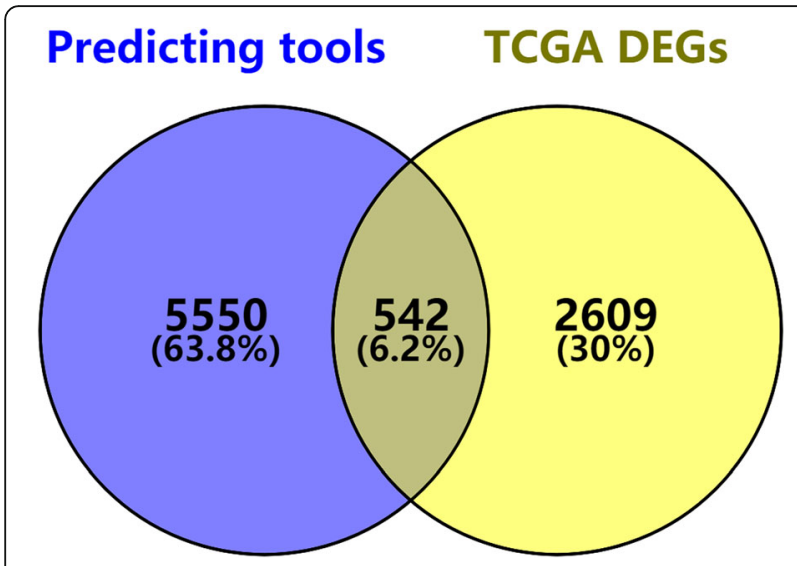

Fig. 13 Venn diagram based on the 12 predicting tools and the differentially expressed genes (DEGs) in TCGA

suggests that miR-198-5p likely plays a role in tumor growth, lymph node metastasis, or distant metastasis. However, the downregulation of miR-198-5p was not obvious in our in-house RT-qPCR analysis. The diagnostic validation and meta-analysis based on GEO and RT-qPCR data indicated that miR-198-5p might be a biomarker of LUSC, but the sensitivity and specificity were not sufficiently high. Similarly, study region may be a source of heterogeneity, which suggested that the diagnostic screening might be suitable for Asian populations but not for others. Apart from LUSC, several studies have explored the expression pattern and mechanism of miR-198-5p in other diseases. MiR-198-5p has been reported to be upregulated in multiple myeloma [14], chronic pancreatitis or pancreatic ductal adenocarcinoma [15], Parkinson's disease [16], esophageal cancer [17], preeclampsia [18], pancreatic adenocarcinoma, ampullary adenocarcinoma [19], lupus nephritis [20], retinoblastoma [21], anencephaly [22], and squamous cell carcinoma of tongue [23]. On the other hand, low expression of

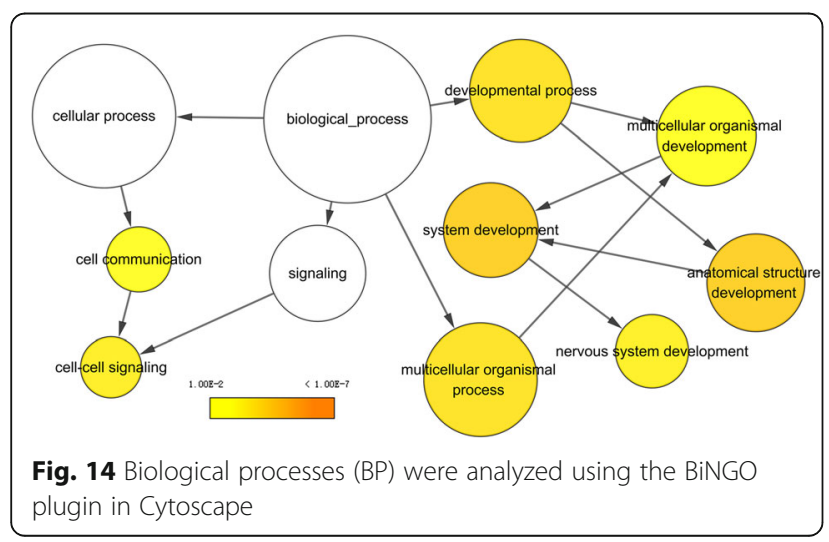

Table 4 The most enriched 10 Gene Ontology (GO) term in biological process (BP) analysis, cellular component (CC), and molecular functions (MF)

\begin{tabular}{|c|c|c|c|}
\hline Category & Term & Count & $P$ value \\
\hline GOTERM_BP_DIRECT & $\begin{array}{l}\text { GO:0008544 epidermis } \\
\text { development }\end{array}$ & 10 & 4.84E-04 \\
\hline GOTERM_BP_DIRECT & $\begin{array}{l}\text { GO:0043524 negative } \\
\text { regulation of neuron } \\
\text { apoptotic process }\end{array}$ & 12 & $9.35 \mathrm{E}-04$ \\
\hline GOTERM_BP_DIRECT & $\begin{array}{l}\text { GO:0008284 positive } \\
\text { regulation of cell proliferation }\end{array}$ & 26 & $9.70 E-04$ \\
\hline GOTERM_BP_DIRECT & $\begin{array}{l}\text { GO:0060070 canonical Wnt } \\
\text { signaling pathway }\end{array}$ & 9 & 0.001824 \\
\hline GOTERM_BP_DIRECT & $\begin{array}{l}\text { GO:0007399 nervous system } \\
\text { development }\end{array}$ & 18 & 0.002211 \\
\hline GOTERM_BP_DIRECT & $\begin{array}{l}\text { GO:0071277 cellular response } \\
\text { to calcium ion }\end{array}$ & 7 & 0.002457 \\
\hline GOTERM_BP_DIRECT & $\begin{array}{l}\text { GO:0007269 neurotransmitter } \\
\text { secretion }\end{array}$ & 7 & 0.002457 \\
\hline GOTERM_BP_DIRECT & $\begin{array}{l}\text { GO:0090103 cochlea } \\
\text { morphogenesis }\end{array}$ & 5 & 0.002641 \\
\hline GOTERM_BP_DIRECT & $\begin{array}{l}\text { GO:0014075 response to } \\
\text { amine }\end{array}$ & 4 & 0.002773 \\
\hline GOTERM_BP_DIRECT & $\begin{array}{l}\text { GO:0006366 transcription } \\
\text { from RNA polymerase II } \\
\text { promoter }\end{array}$ & 26 & 0.003531 \\
\hline GOTERM_CC_DIRECT & GO:0030054 cell junction & 29 & $7.60 \mathrm{E}-05$ \\
\hline GOTERM_CC_DIRECT & $\begin{array}{l}\text { GO:0005667 transcription } \\
\text { factor complex }\end{array}$ & 15 & $9.32 \mathrm{E}-04$ \\
\hline GOTERM_CC_DIRECT & GO:0008021 synaptic vesicle & 10 & $9.61 \mathrm{E}-04$ \\
\hline GOTERM_CC_DIRECT & GO:0009986 cell surface & 29 & 0.001109 \\
\hline GOTERM_CC_DIRECT & GO:0045202 synapse & 13 & 0.004398 \\
\hline GOTERM_CC_DIRECT & $\begin{array}{l}\text { GO:0005876 spindle } \\
\text { microtubule }\end{array}$ & 6 & 0.006912 \\
\hline GOTERM_CC_DIRECT & $\begin{array}{l}\text { GO:0042734 presynaptic } \\
\text { membrane }\end{array}$ & 7 & 0.007013 \\
\hline GOTERM_CC_DIRECT & GO:0043195 terminal bouton & 7 & 0.007013 \\
\hline GOTERM_CC_DIRECT & GO:0098793 presynapse & 7 & 0.008171 \\
\hline GOTERM_CC_DIRECT & $\begin{array}{l}\text { GO:0005887 integral } \\
\text { component of plasma } \\
\text { membrane }\end{array}$ & 55 & 0.008929 \\
\hline GOTERM_MF_DIRECT & $\begin{array}{l}\text { GO:0046983 protein } \\
\text { dimerization activity }\end{array}$ & 15 & 8.03E-05 \\
\hline GOTERM_MF_DIRECT & $\begin{array}{l}\text { GO:0005509 calcium ion } \\
\text { binding }\end{array}$ & 36 & $9.88 \mathrm{E}-04$ \\
\hline GOTERM_MF_DIRECT & $\begin{array}{l}\text { GO:0016810 hydrolase activity, } \\
\text { acting on carbon-nitrogen (but } \\
\text { not peptide) bonds }\end{array}$ & 4 & 0.00922 \\
\hline GOTERM_MF_DIRECT & GO:0005109 frizzled binding & 5 & 0.017408 \\
\hline GOTERM_MF_DIRECT & $\begin{array}{l}\text { GO:0001105 RNA polymerase } \\
\text { II transcription coactivator } \\
\text { activity }\end{array}$ & 5 & 0.019099 \\
\hline GOTERM_MF_DIRECT & $\begin{array}{l}\text { GO:0043565 sequence-specific } \\
\text { DNA binding }\end{array}$ & 24 & 0.019304 \\
\hline GOTERM_MF_DIRECT & $\begin{array}{l}\text { GO:0008080 N-acetyltransferase } \\
\text { activity }\end{array}$ & 4 & 0.022413 \\
\hline GOTERM_MF_DIRECT & GO:0003682 chromatin binding & 19 & 0.026956 \\
\hline GOTERM_MF_DIRECT & $\begin{array}{l}\text { GO:0001077 transcriptional activator activity, } \\
\text { RNA polymerase Il core promoter proximal } \\
\text { region sequence-specific binding }\end{array}$ & 13 & 0.033582 \\
\hline GOTERM_MF_DIRECT & GO:0005262 calcium channel activity & 6 & 0.045673 \\
\hline
\end{tabular}




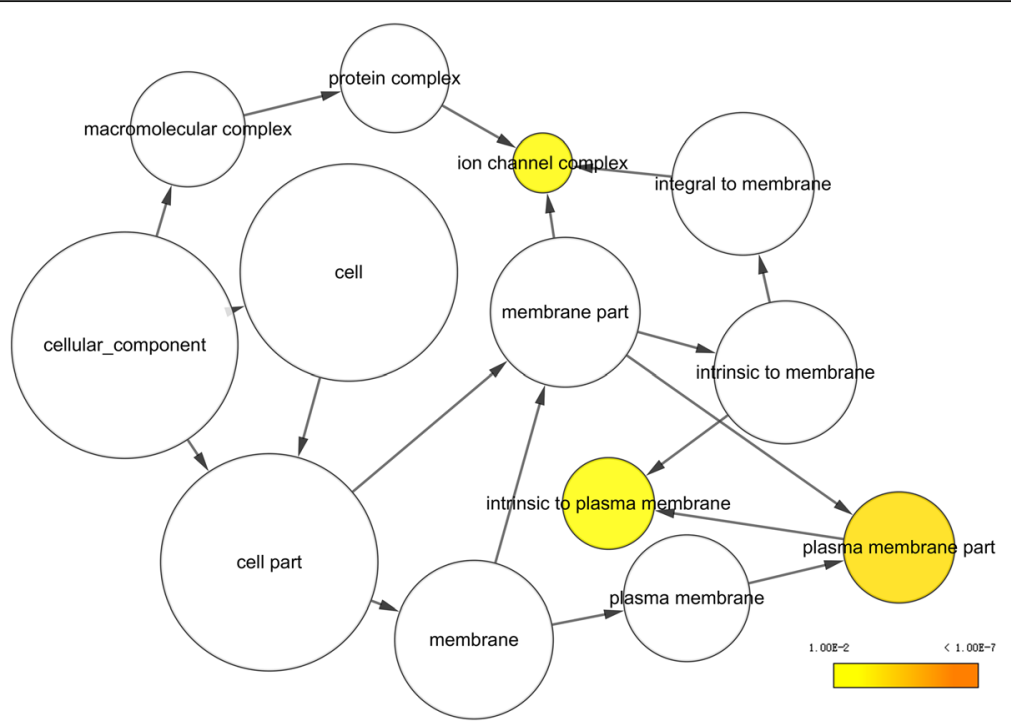

Fig. 15 Cellular components (CC) were analyzed using the BiNGO plugin in Cytoscape

miR-198-5p has been found in prostate cancer [24], breast cancer [25], glioblastoma [26, 27], hepatocellular carcinoma [28], especially hepatitis C virusassociated hepatocellular carcinoma $[29,30]$, osteosarcoma [31], gastric cancer [32], colorectal cancer [33], pancreatic cancer [34], and respiratory syncytial virus (RSV) infection [35]. The overexpression of miR-198-5p has also been documented in CD8+ T cells in renal cell carcinoma [36]. In prostate cancer, a recent study indicated that miR-198-5p is targeted by the long noncoding RNA SChLAP1, leading to the activation of the MAPK1 pathway, thereby promoting cancer cell proliferation and metastasis [24]. Another study suggested that miR-198-5p may be involved in prostate cancer [37]. In hepatocellular carcinoma, miR-198-5p has been shown to target the HGF/c-MET pathway [38]. Several studies have revealed that the expression of miR-198-5p is greatly related to lymph node metastasis or distant metastasis in different malignant diseases, such as breast cancer [25], osteosarcoma [31], gastric cancer [32], and colorectal cancer [33]. Some studies have also shown that miR-198-5p is closely related to cell proliferation, apoptosis, and migration [12, $14,39,40]$. The relationship between miR-198-5p and cancer prognosis is controversial $[15,17,27,32-34]$. Thus, we

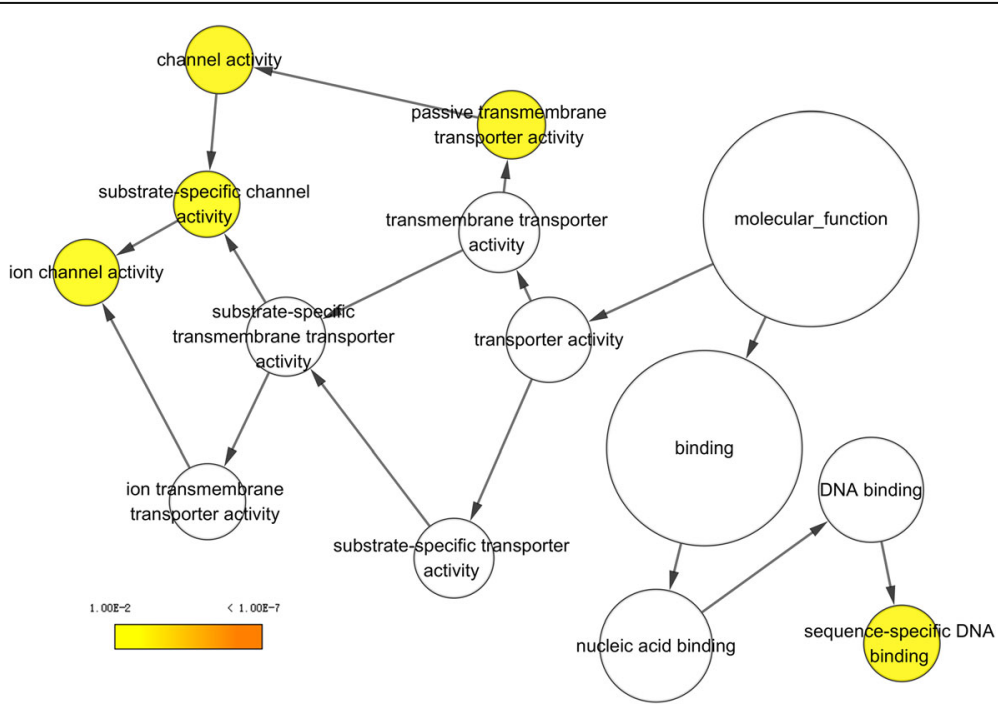

Fig. 16 Molecular functions (MF) were analyzed using the BiNGO plugin in Cytoscape 


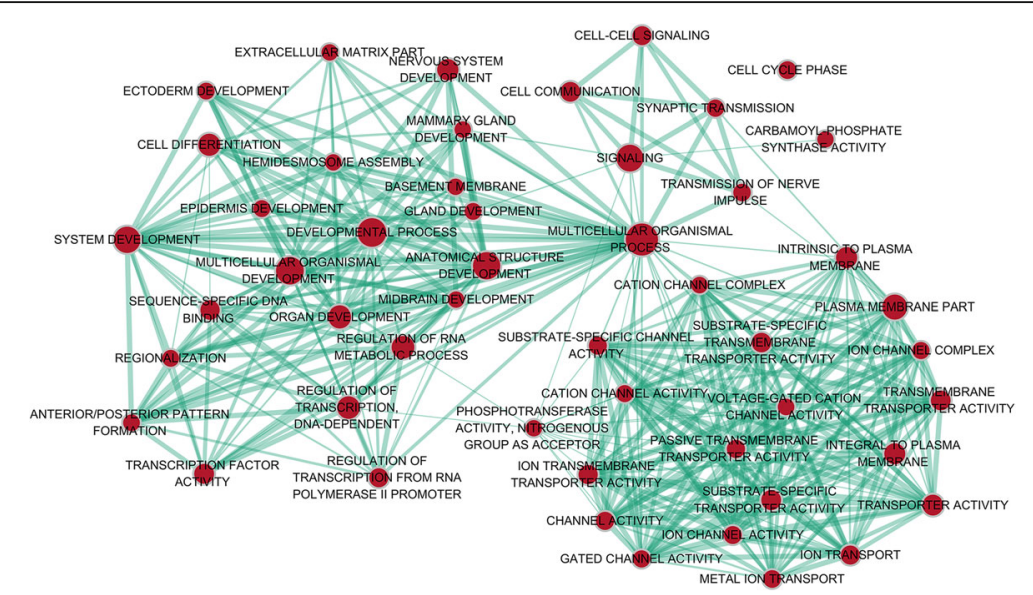

Fig. 17 Kyoto Encyclopedia of Genes and Genomes (KEGG) pathway analysis was performed using the EnrichmentMap plugin in Cytoscape

Table 5 Kyoto Encyclopedia of Genes and Genomes (KEGG) pathway annotation of the putative target genes of miR-198-5p

\begin{tabular}{|c|c|c|c|}
\hline Category & Term & Count & $P$ value \\
\hline KEGG_PATHWAY & $\begin{array}{l}\text { hsa05223:Non-small cell lung } \\
\text { cancer }\end{array}$ & 7 & 0.002996 \\
\hline KEGG_PATHWAY & hsa05200:Pathways in cancer & 20 & 0.005776 \\
\hline KEGG_PATHWAY & hsa05212:Pancreatic cancer & 7 & 0.006302 \\
\hline KEGG_PATHWAY & hsa05214:Glioma & 7 & 0.006302 \\
\hline EGG_PATHWAY & hsa04512:ECM-receptor interaction & 8 & 0.00691 \\
\hline EG_PATHWAY & $\begin{array}{l}\text { hsa04151:PI3K-Akt signaling } \\
\text { pathway }\end{array}$ & 17 & 0.015931 \\
\hline KEGG_PATHWAY & hsa04360:Axon guidance & 9 & 0.016478 \\
\hline VAY & hsa0s & 5 & 0. \\
\hline KEGG_PATHWAY & hsa05222:Small cell lung cancer & 7 & 0.021937 \\
\hline KEGG_PATHWAY & $\begin{array}{l}\text { hsa04550:Signaling pathways } \\
\text { regulating pluripotency of } \\
\text { stem cells }\end{array}$ & 9 & 0. \\
\hline KEGG_PATHWAY & hsa05166:HTLV-I infection & 13 & 0.032302 \\
\hline KEGG_PATHWAY & hsa05218:Melanoma & 6 & 0.035606 \\
\hline KEGG_PATHWAY & hsa00 & 10 & 0.037636 \\
\hline KEGG_PATHWAY & hsa04390:Hippo signaling pathway & 9 & 0.040805 \\
\hline KEGG_PATHWAY & hsa03410:Base excision repair & 4 & 0.05213 \\
\hline KEGG_PATHWAY & $\begin{array}{l}\text { hsa00250:Alanine, aspartate and } \\
\text { glutamate metabolism }\end{array}$ & 4 & 0.060271 \\
\hline KEGG_PATHWAY & hsa05206:MicroRNAs in cancer & 13 & 0.063619 \\
\hline KEGG_PATHWAY & hsa04014:Ras signaling pathway & 11 & 0.066327 \\
\hline KEGG_PATHWAY & hsa04724:Glutamatergic synapse & 7 & 0.073405 \\
\hline KEGG_PATHWAY & $\begin{array}{l}\text { hsa05230:Central carbon } \\
\text { metabolism in cancer }\end{array}$ & 5 & 0.082196 \\
\hline KEGG_PATHWAY & hsa05033:Nicotine addiction & 4 & 0.083009 \\
\hline KEGG_PATHWAY & hsa04510:Focal adhesion & 10 & 0.084102 \\
\hline
\end{tabular}

investigated whether miR-198-5p plays an important role in biological processes in various diseases, both malignant and benign.

In the case of lung adenocarcinoma, two reports have verified that miR-198-5p is under-expressed [12, 41]. However, studies on the characteristic of miR-198-5p in LUSC are lacking. One study assessed the diagnostic significance of miR-198-5p in lung adenocarcinoma, with sensitivity $=71.1 \%$, specificity $=95.2 \%$, and AUC $=0.887$ (95\% CI 0.801, 0.945) [41]. Our study highlighted the diagnostic value of miR-198-5p in LUSC. Yang et al. showed that miR-198-5p was capable to suppress proliferation and promote apoptosis in lung cancer cells by targeting FGFR1 [12], and Wu et al. showed that miR198-5p promotes apoptosis, represses cell proliferation, and leads to cell cycle arrest in lung adenocarcinoma cells by directly targeting SHMT1 [39]. Our study showed that expression pattern and diagnostic value of miR-198-5p varied according to the race of the patient population, which should be further validated in larger samples.

Although many studies use prediction tools to determine miRNA target genes, the inadequate number of available prediction tools can lead to unreliable data. We used 12 online prediction tools based on miRWalk 2.0, and this method had not been previously utilized in LUSC. The predicted genes were cross-referenced with the differentially expressed genes in TCGA, which further enhanced the specificity and accuracy of our investigation. Because miR-198-5p is downregulated in LUSC, we chose the upregulated genes from TCGA. Via bioinformatics analyses, the putative target genes of miR-198-5p were most significantly enriched in the KEGG pathways of non-small cell lung cancer, pathways in cancer, pancreatic cancer, glioma, and ECM-receptor 


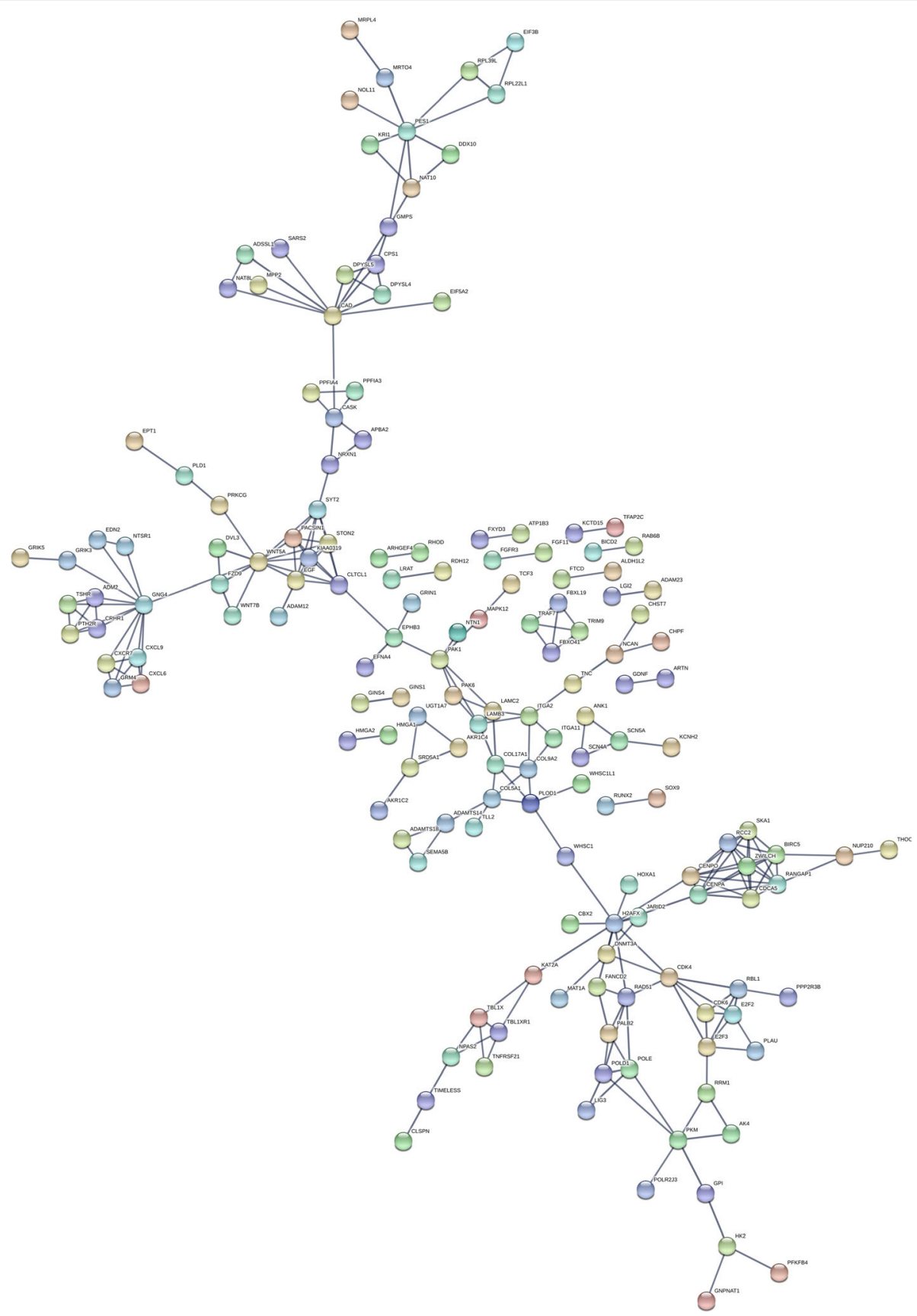

Fig. 18 Protein-protein interaction (PPI) networks with 537 nodes and 848 edges were constructed using STRING. The PPI enrichment $P$ value was 1.7E-14. Disconnected nodes were hidden in the network

interactions. For the $\mathrm{GO}$ biological processes, the putative target genes of miR-198-5p were involved in epidermis development, negative regulation of neuron apoptotic processes, positive regulation of cell proliferation, the canonical Wnt signaling pathway, and nervous system development, which indicated that the putative target genes might regulated epidermis proliferation, cell apoptosis, or carcinoma of nervous tissues. In addition, for the GO cellular components, the putative target genes of miR-198-5p were enriched in cell junction, transcription factor complex, synaptic vesicle, cell surface proteins, and synapses, which are related to migration, metastasis, and intercellular exchange of molecules. In terms of the GO molecular functions, the putative target genes of miR-198-5p were associated with protein dimerization activity, calcium ion binding, 

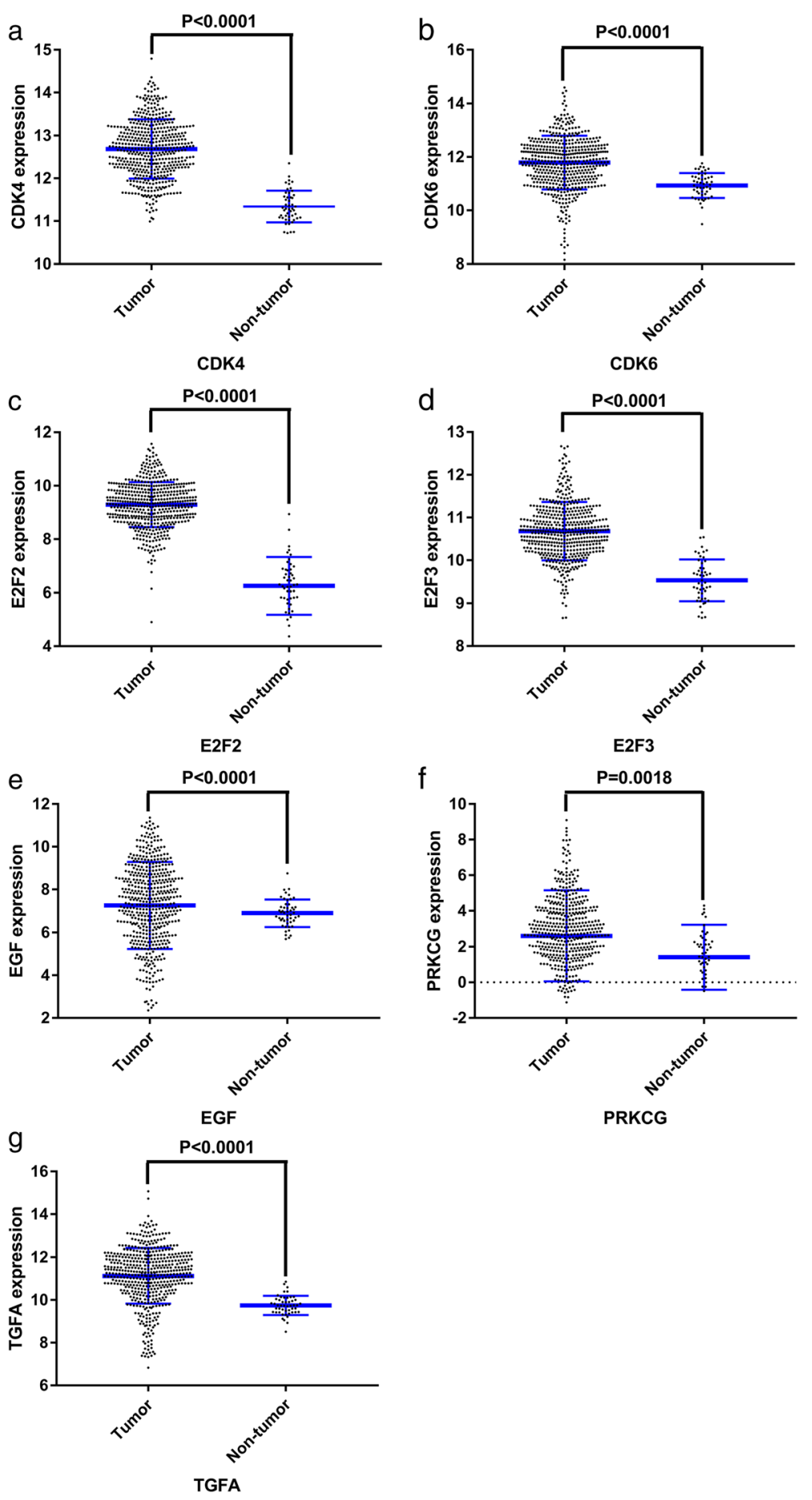

Fig. 19 Scatterplots of the seven chosen genes from the Cancer Genome Atlas (TCGA). a CDK4. b CDK6. c E2F2. d E2F3. e EGF. f PRKCG. g TGFA

hydrolase activity on carbon-nitrogen (but not peptide) bonds, frizzled binding, and RNA polymerase II transcription co-activator activity. To verify the accuracy of our analysis, we selected several genes and determined its expression based on TCGA. The genes included the pathway non-small cell lung cancer were E2F2, E2F3,
TGFA, PRKCG, CDK6, EGF, and CDK4, which were all expressed at significantly higher levels in LUSC tissues in comparison to that in the non-cancer group. Thus, these genes are probably the targets of miR-198-5p. The putative target genes of miR-198 should be validated further in the future. 

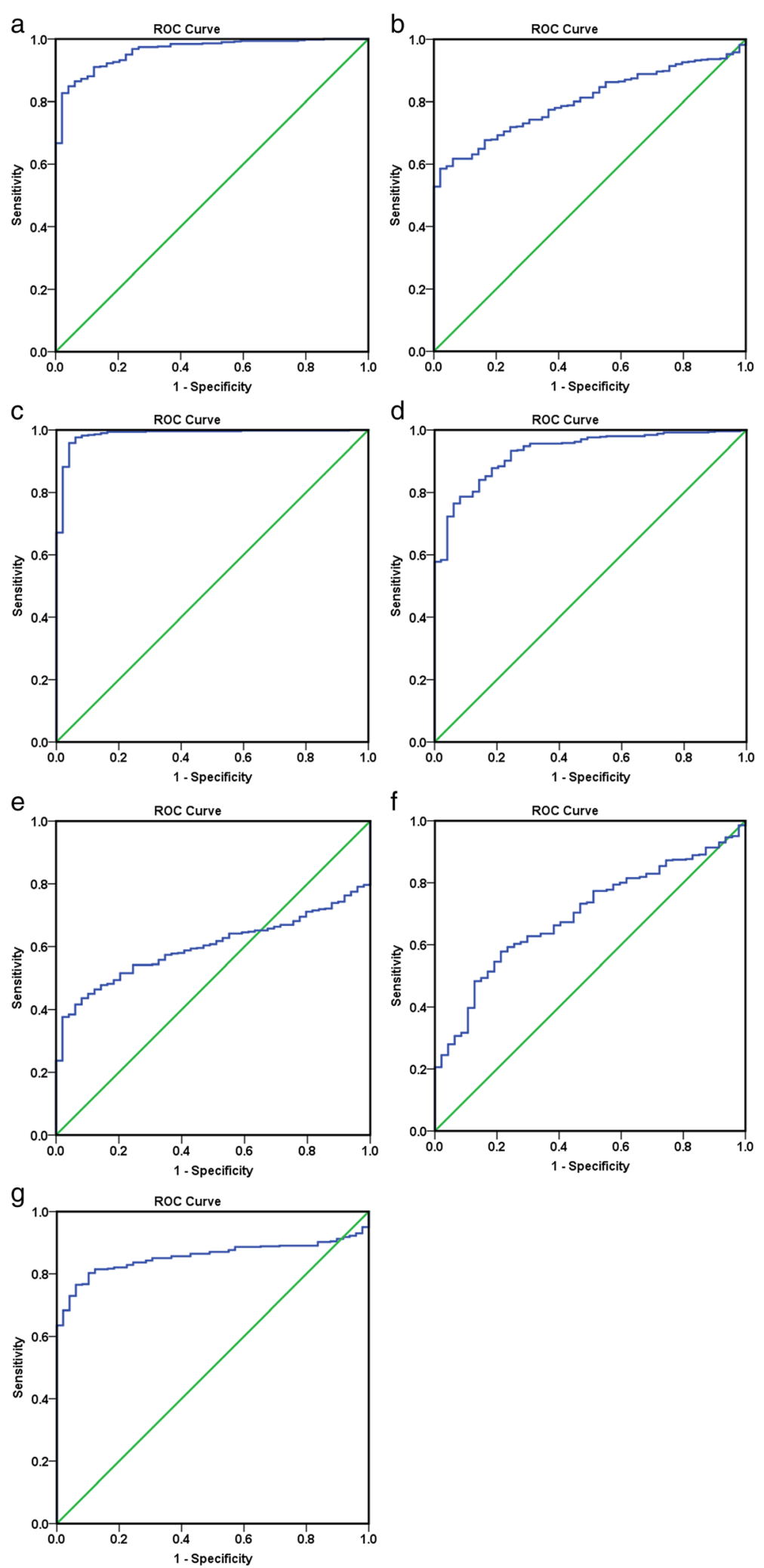

Fig. 20 Receiver operating characteristic (ROC) curves of the seven chosen genes from the Cancer Genome Atlas (TCGA). a CDK4. b CDK6. c E2F2. d E2F3. e EGF. f PRKCG. g TGFA 


\section{Conclusions}

MiR-198-5p might be downregulated in LUSC, especially in Asia region. The putative target genes of miR-198-5p were closely related to tumorigenesis and progress in LUSC.

\section{Abbreviations}

LUSC: Lung squamous cell carcinoma; GEO: Gene Expression Omnibus: FFPE: Formalin-fixed, paraffin-embedded; mRNA: Messenger RNA; miRNA: Micro RNA; TCGA: The Cancer Genome Atlas; AUC: Area under the curve; SROC: Summarized receiver operating characteristic; NSCLC: Non-small cell lung cancer; GO: Gene Ontology; KEGG: Kyoto Encyclopedia of Genes and Genomes; BP: Biological processes; CC: Cellular components; MF: Molecular functions; PPI: Protein-protein interaction

\section{Acknowledgements}

None.

\section{Funding}

Open fund of Guangxi Colleges and Universities Key Laboratory of Biological Molecular Medicine Research (GXBMR201601), the Youth Science Foundation of Guangxi Medical University (GXMUYSF2014032), and Future Academic Star of Guangxi Medical University (WLXSZX17001) funded this study.

\section{Availability of data and materials}

All data generated or analyzed during this study are included in this published article.

\section{Authors' contributions}

YF, GC, and YG participated in the design of this study. $Y L$ and $J H$ drafted the manuscript. GC, SH, YF, and $Y G$ revised the manuscript. $Y L$ conducted the RT-qPCR. JH performed the statistical analysis. YL, JH, RT, WC, PC, WC, KS, $L G, X G, A L$, and $X P$ contributed to the retrieval of database. All authors read and approved the final manuscript.

\section{Ethics approval and consent to participate}

This study was approved by the Medical Ethics Committee of First Affiliated Hospital of Guangxi Medical University (Approval Number: 2015 (KY-E-041)), and written informed consent was also obtained from each participant.

\section{Consent for publication}

Not applicable.

\section{Competing interests}

The authors declare that they have no competing interests.

\section{Publisher's Note}

Springer Nature remains neutral with regard to jurisdictional claims in published maps and institutional affiliations.

Received: 19 August 2017 Accepted: 16 January 2018

Published online: 02 February 2018

\section{References}

1. Torre LA, Bray F, Siegel RL, Ferlay J, Lortet-Tieulent J, Jemal A. Global cancer statistics, 2012. CA Cancer J Clin. 2015:65:87-108.

2. An HJ, Lee YJ, Hong SA, Kim JO, Lee KY, Kim YK, Park JK, Kang JH. The prognostic role of tissue and serum MMP-1 and TIMP-1 expression in patients with non-small cell lung cancer. Pathol Res Pract. 2016;212:357-64.

3. Siegfried JM, Lin Y, Diergaarde B, Lin HM, Dacic S, Pennathur A, Weissfeld JL, Romkes M, Nukui T, Stabile LP. Expression of PAM50 genes in lung cancer: evidence that interactions between hormone receptors and HER2/HER3 contribute to poor outcome. Neoplasia. 2015:17:817-25.

4. Tajima S, Takanashi Y, Koda K. Squamous cell carcinoma of the lung with highly proliferating fibromatosis-like stroma: a rare phenomenon. Int J Clin Exp Pathol. 2015;8:5870-6.

5. Chiang Y, Yang JC, Hsu FM, Chen YH, Shih JY, Lin ZZ, Lan KH, Cheng AL, Kuo SH. The response, outcome and toxicity of aggressive palliative thoracic radiotherapy for metastatic non-small cell lung cancer patients with controlled extrathoracic diseases. PLoS One. 2015:10:e0145936.

6. Lee $E$, Jin D, Lee BB, Kim Y, Han J, Shim YM, Kim DH. Negative effect of cyclin D1 overexpression on recurrence-free survival in stage II-IIIA lung adenocarcinoma and its expression modulation by vorinostat in vitro. BMC Cancer. 2015;15:982

7. Lin SY, Peng F. Association of SIRT1 and HMGA1 expression in non-small cell lung cancer. Oncol Lett. 2016;11:782-8.

8. Ming F, Sun Q. Epigenetically silenced PTPRO functions as a prognostic marker and tumor suppressor in human lung squamous cell carcinoma. Mol Med Rep. 2017;16:746-54

9. Bartel DP. MicroRNAs: genomics, biogenesis, mechanism, and function. Cell. 2004:116:281-97.

10. Cho WC. MicroRNAs: potential biomarkers for cancer diagnosis, prognosis and targets for therapy. Int J Biochem Cell Biol. 2010;42:1273-81.

11. Dou Z, Lin S, Dai C, Lu Y, Tian T, Wang M, Liu X, Zheng Y, Xu P, Li S, et al. Pooling-analysis for diagnostic and prognostic value of MiRNA-100 in various cancers. Oncotarget. 2017;8:62703-15.

12. Yang J, Zhao H, Xin Y, Fan L. MicroRNA-198 inhibits proliferation and induces apoptosis of lung cancer cells via targeting FGFR1. J Cell Biochem. 2014;115:987-95.

13. Peltier HJ, Latham GJ. Normalization of microRNA expression levels in quantitative RT-PCR assays: identification of suitable reference RNA targets in normal and cancerous human solid tissues. RNA. 2008;14:844-52.

14. Bi C, Chung TH, Huang G, Zhou J, Yan J, Ahmann GJ, Fonseca R, Chng WJ. Genome-wide pharmacologic unmasking identifies tumor suppressive microRNAs in multiple myeloma. Oncotarget. 2015;6:26508-18.

15. Vychytilova-Faltejskova P, Kiss I, Klusova S, Hlavsa J, Prochazka V, Kala Z, Mazanec J, Hausnerova J, Kren L, Hermanova M, et al. MiR-21, miR-34a, miR-198 and miR-217 as diagnostic and prognostic biomarkers for chronic pancreatitis and pancreatic ductal adenocarcinoma. Diagn Pathol. 2015;10:38.

16. Cardo LF, Coto E, Ribacoba R, Menendez M, Moris G, Suarez E, Alvarez V. MiRNA profile in the substantia nigra of Parkinson's disease and healthy subjects. J Mol Neurosci. 2014:54:830-6.

17. Qi B, Yao WJ, Zhao BS, Qin XG, Wang Y, Wang WJ, Wang TY, Liu SG, Li HC Involvement of microRNA-198 overexpression in the poor prognosis of esophageal cancer. Asian Pac J Cancer Prev. 2013;14:5073-6.

18. Choi SY, Yun J, Lee OJ, Han HS, Yeo MK, Lee MA, Suh KS. MicroRNA expression profiles in placenta with severe preeclampsia using a PNA-based microarray. Placenta. 2013;34:799-804.

19. Schultz NA, Werner J, Willenbrock H, Roslind A, Giese N, Horn T, Wojdemann M, Johansen JS. MicroRNA expression profiles associated with pancreatic adenocarcinoma and ampullary adenocarcinoma. Mod Pathol. 2012;25:1609-22.

20. Lu J, Kwan BC, Lai FM, Tam LS, Li EK, Chow KM, Wang G, Li PK, Szeto CC Glomerular and tubulointerstitial miR-638, miR-198 and miR-146a expression in lupus nephritis. Nephrology (Carlton). 2012;17:346-51.

21. Zhao JJ, Yang J, Lin J, Yao N, Zhu Y, Zheng J, Xu J, Cheng JQ, Lin JY, Ma X Identification of miRNAs associated with tumorigenesis of retinoblastoma by miRNA microarray analysis. Childs Nerv Syst. 2009;25:13-20.

22. Zhang Z, Chang H, Li Y, Zhang T, Zou J, Zheng X, Wu J. MicroRNAs: potential regulators involved in human anencephaly. Int J Biochem Cell Biol. 2010;42:367-74

23. Wong TS, Liu XB, Wong BY, Ng RW, Yuen AP, Wei WI. Mature miR-184 as potential oncogenic microRNA of squamous cell carcinoma of tongue. Clin Cancer Res. 2008;14:2588-92.

24. Li Y, Luo H, Xiao N, Duan J, Wang Z, Wang S. Long noncoding RNA SChLAP1 accelerates the proliferation and metastasis of prostate cancer via targeting miR-198 and promoting the MAPK1 pathway. Oncol Res. 2017

25. Hu Y, Tang Z, Jiang B, Chen J, Fu Z. miR-198 functions as a tumor suppressor in breast cancer by targeting CUB domain-containing protein 1. Oncol Lett 2017:13:1753-60.

26. Nie E, Jin X, Wu W, Yu T, Zhou X, Shi Z, Zhang J, Liu N, You Y. MiR-198 enhances temozolomide sensitivity in glioblastoma by targeting MGMT. J Neuro-Oncol. 2017;133:59-68.

27. Man HB, Bi WP, Man HH. Decreased microRNA-198 expression and its prognostic significance in human glioma. Genet Mol Res. 2016;15

28. Huang WT, Wang HL, Yang $H$, Ren FH, Luo YH, Huang CQ, Liang YY, Liang HW, Chen G, Dang YW. Lower expressed miR-198 and its potential targets in hepatocellular carcinoma: a clinicopathological and in silico study. Onco Targets Ther. 2016;9:5163-80. 
29. Elfimova N, Sievers E, Eischeid H, Kwiecinski M, Noetel A, Hunt H, Becker D, Frommolt P, Quasdorff M, Steffen HM, et al. Control of mitogenic and motogenic pathways by miR-198, diminishing hepatoma cell growth and migration. Biochim Biophys Acta. 1833;2013:1190-8.

30. Varnholt H, Drebber U, Schulze F, Wedemeyer I, Schirmacher P, Dienes HP, Odenthal M. MicroRNA gene expression profile of hepatitis $C$ virusassociated hepatocellular carcinoma. Hepatology. 2008;47:1223-32.

31. Zhang S, Zhao Y, Wang L. MicroRNA-198 inhibited tumorous behaviors of human osteosarcoma through directly targeting ROCK1. Biochem Biophys Res Commun. 2016;472:557-65.

32. Cui Z, Zheng X, Kong D. Decreased miR-198 expression and its prognostic significance in human gastric cancer. World J Surg Oncol. 2016;14:33.

33. Wang $\mathrm{M}$, Wang J, Kong $\mathrm{X}$, Chen $\mathrm{H}$, Wang $\mathrm{Y}$, Qin $\mathrm{M}$, Lin Y, Chen $\mathrm{H}, \mathrm{Xu}$ J, Hong J, et al. MiR-198 represses tumor growth and metastasis in colorectal cancer by targeting fucosyl transferase 8. Sci Rep. 2014:4:6145.

34. Marin-Muller C, Li D, Bharadwaj U, Li M, Chen C, Hodges SE, Fisher WE, Mo Q, Hung MC, Yao Q. A tumorigenic factor interactome connected through tumor suppressor microRNA-198 in human pancreatic cancer. Clin Cancer Res. 2013;19:5901-13.

35. Bakre A, Mitchell P, Coleman JK, Jones LP, Saavedra G, Teng M, Tompkins SM, Tripp RA. Respiratory syncytial virus modifies microRNAs regulating host genes that affect virus replication. J Gen Virol. 2012;93:2346-56.

36. Gigante M, Pontrelli P, Herr W, Gigante M, D'Avenia M, Zaza G, Cavalcanti E, Accetturo M, Lucarelli G, Carrieri G, et al. miR-29b and miR-198 overexpression in CD8+ T cells of renal cell carcinoma patients downmodulates JAK3 and MCL-1 leading to immune dysfunction. J Transl Med. 2016;14:84.

37. Ye L, Li S, Ye D, Yang D, Yue F, Guo Y, Chen X, Chen F, Zhang J, Song X. Livin expression may be regulated by miR-198 in human prostate cancer cell lines. Eur J Cancer. 2013;49:734-40.

38. Tan S, Li R, Ding K, Lobie PE, Zhu T. miR-198 inhibits migration and invasion of hepatocellular carcinoma cells by targeting the HGF/C-MET pathway. FEBS Lett. 2011;585:2229-34.

39. Wu S, Zhang G, Li P, Chen S, Zhang F, Li J, Jiang C, Chen X, Wang Y, Du Y, et al. miR-198 targets SHMT1 to inhibit cell proliferation and enhance cell apoptosis in lung adenocarcinoma. Tumour Biol. 2016;37:5193-202.

40. Wang J, Dan G, Shangguan T, Hao H, Tang R, Peng K, Zhao J, Sun H, Zou Z. miR-198 represses the proliferation of HaCaT cells by targeting cyclin D2. Int J Mol Sci. 2015;16:17018-28.

41. Han HS, Yun J, Lim SN, Han JH, Lee KH, Kim ST, Kang MH, Son SM, Lee YM, Choi SY, et al. Downregulation of cell-free miR-198 as a diagnostic biomarker for lung adenocarcinoma-associated malignant pleural effusion. Int J Cancer. 2013;133:645-52.

\section{Submit your next manuscript to BioMed Central and we will help you at every step:}

- We accept pre-submission inquiries

- Our selector tool helps you to find the most relevant journal

- We provide round the clock customer support

- Convenient online submission

- Thorough peer review

- Inclusion in PubMed and all major indexing services

- Maximum visibility for your research

Submit your manuscript at www.biomedcentral.com/submit

) Biomed Central 